NBER WORKING PAPER SERIES

\title{
EQUILIBRIUM HEALTH SPENDING AND POPULATION AGING IN A MODEL OF ENDOGENOUS GROWTH - WILL THE GDP SHARE OF HEALTH SPENDING KEEP RISING?
}

\author{
Isaac Ehrlich \\ Yong Yin
}

Working Paper 19856

http://www.nber.org/papers/w19856

\author{
NATIONAL BUREAU OF ECONOMIC RESEARCH \\ 1050 Massachusetts Avenue \\ Cambridge, MA 02138 \\ January 2014
}

An earlier version of this paper was presented at the Conference on Health, Aging, and Human Capital, co-sponsored by Rand Corporation and the UB Center for Human Capital and held in Santa Monica on December 2-3,2011. We acknowledge helpful comments from participants at that conference. We also benefitted from comments on later versions from participants in seminars held at IZA in Bonn on May 27, 2013 and at the Rand Corporation on June 12, 2013, and from numerous comments and suggestions by Jinyoung Kim. The views expressed herein are those of the authors and do not necessarily reflect the views of the National Bureau of Economic Research.

NBER working papers are circulated for discussion and comment purposes. They have not been peerreviewed or been subject to the review by the NBER Board of Directors that accompanies official NBER publications.

(C) 2014 by Isaac Ehrlich and Yong Yin. All rights reserved. Short sections of text, not to exceed two paragraphs, may be quoted without explicit permission provided that full credit, including $\odot$ notice, is given to the source. 
Equilibrium Health Spending and Population Aging in a Model of Endogenous Growth - Will the GDP Share of Health Spending Keep Rising?

Isaac Ehrlich and Yong Yin

NBER Working Paper No. 19856

January 2014, March 2014

JEL No. I1,I15,J11,J17,J24,O4

\begin{abstract}
The apparently unrelenting growth in the GDP-share of health spending (SHS) has been a perennial issue of policy concern. Does an equilibrium limit exist? The issue has been left open in recent dynamic models which take income growth and population aging as given. We view these variables as endogenously determined within an overlapping-generations, human-capital-based endogenous-growth model, where a representative parent makes all life-cycle consumption and investment decisions and life and health protection are subject to diminishing returns. Our prototype model, allowing for both quantity and quality of life as desired goods, yields equilibrium upper bounds for SHS. Our calibrated simulations also account for observed trends in reproductive choices, population aging, life expectancy, and economic growth. The analysis offers new insights about factors that drive long-term trends in aging and health spending and establishes a direct relation between health investments at young age and the equilibrium, steady-state rate of economic growth.
\end{abstract}

Isaac Ehrlich

415 Fronczak Hall

State University of New York at Buffalo

and Center for Human Capital

Box 601520

Buffalo, NY 14260-1520

and NBER

mgtehrl@buffalo.edu

Yong Yin

415 Fronczak Hall

State University of New York at Buffalo

and Center for Human Capital

Box 601520

Buffalo, NY 14260

yyin@buffalo.edu 


\section{Introduction}

The continuing growth in the GDP share of health spending in the US has been a perennial issue of academic and policy concerns over the last 5 decades. As Figure 1 indicates, the share has risen from $5.19 \%$ in 1960 to $17.6 \%$ in 2010 . Among the three spending components by source of financing, the fastest growth has been in Medicare and Medicaid, which increased more than 10-fold since 1967. Going forward, the actuaries at the Center for Medicare and Medicaid forecast total health spending to rise at the rate of GDP growth $+1 \%$ per annum. Such expansion is untenable over the long haul. We address two basic questions: a. Does an equilibrium upper-bound exist? $\mathrm{b}$. what are the major forces that drive the expansion in health spending and the dynamic interaction between the latter and economic growth?

Current literature has dealt with these issues in different ways, but has viewed them primarily in a static macro-economic environment or via dynamic models based on exogenously given trends of income growth and demographic changes. There have been much fewer attempts to consider the issue in a model of endogenous growth where population aging and health spending are endogenously determined (but see Ehrlich and Kim, 2005). The literature that links health spending to GDP trends via a formal model (see especially Hall and Jones [HJ], 2007), has not attempted to endogenize income growth and demographic changes, which are thought to be major factors behind the growing share of health spending in GDP (SHS in GDP). Furthermore, growth in per-capita income, trends in fertility and longevity, and the evolution of medical technology seem to be highly interdependent.

These interdependencies can be described by a circular diagram (see Figure 2): the growth of health spending is influenced by the aging of the population brought about by rising longevity and generally falling fertility trends. The latter are part of the demographic transition 
which has been common to all countries that have successfully attained a regime of selfsustaining growth, powered by technological progress or innovative human capital - knowledge, education, and skill formation. And technological innovations, including medical, which lead to per-capita income growth, exert distinct effects on the demand for health and health spending. But causal effects can go in opposite direction as well: a major channel our paper tries to unlock is the impact of specific types of health spending on economic growth. It follows, then, that an endogenous growth model (EGM), which views all the preceding variables as simultaneously determined, may provide better insights concerning future trends in all.

We offer a prototype model that attempts to accomplish this task using an overlappinggenerations endogenous growth model with human-knowledge capital serving as engine of growth. The model features three co-existing generations of representative old parents, young parents, and children, and three phases of life: young age, adulthood, and old age. Altruistic young parents make all consumption and investment decisions in their own health and their children's knowledge and health. The model can thus account for reproductive choices, survival probabilities to adulthood and old age, consumption and health spending over the life cycle and across generations, and endogenous growth in per-capita income powered by persistent human knowledge formation and discrete technological advances as well.

This type of human-capital based endogenous growth model (EGM) has been developed and applied in a number of previous works (e.g., Becker, Murphy, and Tumura, 1991, Ehrlich and Lui [EL], 1991, and Ehrlich and Kim [EK], 2007). The novelty of the current model is that it treats survival probabilities to adulthood and old age as additional endogenous variables, thus accounting for life expectancy and population aging as well. In the extended version of the model, we also allow health maintenance within any given phase of life to produce "health 
benefits" as an independent consumption good. The implicit derived-demand for health spending stems, therefore, from the role of health care in promoting longevity and health maintenance, or what Ehrlich and Chuma (1990) called the "quantity and quality of life".

Both the basic and extended prototype models are limited by a number of simplifying assumptions. All choices are made by individuals, i.e., the model is essentially that of a competitive economy comprised of independent representative agents. For simplicity, we allow for the existence of a fully balanced, pay-as-you-go social security system of defined benefits that works as a kind of annuities markets to eschew the need to account for physical capital in our analysis. ${ }^{1}$ There is thus no government subsidization of health care services through Medicare or Medicaid, nor does the model account for any moral hazard stemming from asymmetric information or an actuarially unfair insurance system.

Furthermore, the model does not allow for an expanding number of overlapping generations and corresponding life phases as longevity keeps growing. We leave the development of such extensions for future work. For these reasons, the model cannot be expected to forecast precisely the steady-state levels of life expectancy and SHS in GDP under current parameters. Yet the model is sufficiently general to allow us to analyze the role of the main factors driving population aging and life expectancy trends, the rising SHS in the economy, as well as the role of health in economic growth.

More specifically, we aim to address the following key issues: Can SHS reach a steady state level in a balanced-endogenous-growth equilibrium? If so, what can be said about the economic forces leading to this level and their dynamic evolution? And what would be the impact of shifts in the basic parameters dictating these paths? Also, is the growth in health 
spending just a derivative of economic growth or does some health spending affect economic growth as well? If so, what policy insights follow from such mutual interdependencies?

Part I features our basic setup. In part II we present a baseline model where health spending is restricted to include investments in life-protection which affect the probabilities of survival from young age to adulthood and from adulthood to old age i.e., the quantity of life. These investments are determined along with fertility and investment in knowledge capital, and thus population aging, consumption, and income growth. In part III we extend the model by recognizing health maintenance and remedial medical care as a separate, but related source of health spending which enhances the quality of life by providing distinct health benefits along with ordinary consumption. We solve the extended model and its nested baseline model numerically via calibrated simulations analyzed in part IV. In part V we summarize the model's implications about the main forces driving the expansion of SHS, and in part VI we discuss some empirical evidence bearing on health and growth. We conclude by highlighting the model's policy inferences and the insights it offers about the impact of investment in education and health on economic growth.

\section{The Basic Setup}

We specify a representative-agent model comprised of three overlapping generations and corresponding discrete phases of life: young age, adulthood, and old age. ${ }^{2}$ Survival from one phase to the other is uncertain. Young parents are the only earners in the economy and make all life-cycle choices: rearing, educating, and protecting their children while securing their own adulthood and old-age needs. Parents are motivated by altruism (companionship) toward their children. $^{3}$ 
The economic environment: The economy is fully competitive. Labor $(L)$ is homogeneous, and its supply per parent is fixed by the productive time constraint per period $(=1)$. Output of goods is a function of labor time and production capacity per worker, $\left(H^{0}+H_{t}\right)$, where $H_{t}$ is the stock of human knowledge of the current generation's representative worker, and $H^{0}$ is endowed physical ability defined in units of $H_{t}$. Assuming a linear goods-production technology, and given a zero-profits condition for firms, "full-income" per capita equals $(Y / L)=w\left(H^{0}+H_{t}\right)$. This yields a time-invariant rental rate per unit of production capacity, $w=1$, which also assures full employment.

Health v. human capital: As the source of production capacity, human capital may in principle include both knowledge (education, experience, skill) and health components. But lumping together these components would defy the objective of disentangling the specific role of health from that of productive knowledge. To sharpen the distinction, we ascribe the level of production capacity and its evolution over succeeding generations $(t)$ to knowledge capital which each generation of parents produces by investing in the education of their children $\left(h_{t}\right)$, and which becomes operational as the latter reach adulthood. The continuous formation of knowledge capital $\left(H_{t}\right)$ thus serves as the economy's engine of per-capita income growth. By contrast, we view health as an asset contributing to the quantity and quality of life.

In the baseline model health is viewed as an implicit asset which protects future survival, and hence the survival of knowledge capital as well. Health is thus represented by the conditional probabilities of survival to phase $\mathrm{j}, \pi_{j, t}$, as they evolve over discrete phases of the life-cycle $(j)$ and across overlapping generations $(t)$. The magnitudes of these probabilities, and hence life expectancy, in turn, are affected by parental investments in their children's as well as their own life protection $\left(I_{j t}\right)$ which range from proper diet and exercise to spending on preventive and life- 
saving health services and related medical research. In our extended model, however, we treat health also as an asset conferring consumption benefits that are derived via spending on health maintenance and remedial medical care $\left(M_{j t}\right)$, conditional on survival. ${ }^{4}$

The engine of growth: The representative agent's education or knowledge capital at adulthood powers productivity and per-capita income growth across generations of adults. The production function requires, however, direct interaction between parents and children:

(1) $H_{\mathrm{t}+1}=A\left(H^{0}+H_{t}\right) h_{\mathrm{t}}$,

where $\mathrm{H}_{t}$ and $\mathrm{H}_{t+1}$ measure the human capital attainments of parents and children; $h_{t}$ denotes investment in education as a fraction of production capacity allocated by the parent toward building knowledge in the child, and $\mathrm{A}$ is a knowledge-transfer technological parameter. Note that by this specification, all investments in human capital are restricted to be made by parents at the offspring's young age. By equation (1) a necessary condition for the existence of a steady state of growth in human capital, and thus in per-capita income is that $\mathrm{Ah}>1$.

Survival from young age to adulthood and from adulthood to old age: Survival is uncertain. It is determined by corresponding conditional probabilities: $\pi_{l}$ is the probability of survival of children to adulthood given birth (the probability of which is taken to be 1 ), and $\pi_{2}$ is the conditional probability of parents' survival to old age, given survival to adulthood. Young parents affect these probabilities through health investments in life protection, $I_{1}$ and $I_{2}$. The endogenous choice variables for young parents thus include: investments in the quantity $(n)$ and well-being of children, $\left(v n_{t}\right)$; children's knowledge capital $\left(n_{t} h_{t}\right)$ and survival to adulthood $\left(n_{t} I_{t t}\right)$; as well as their own survival to old age $\left(I_{2 t}\right)$ and well-being through "savings" $\theta-$ all stated as fractions of production capacity. 


\section{The Baseline Model}

In the baseline model the choice variables are investment in the quantity, knowledge capital and life protection of children, as well as their own life protection and consumption. Accordingly, the outcome variables are specified as follows:

Consumption per parent at young adulthood: This variable is constrained by the parent's full income at the productive phase of life, net of education and health investments and savings:

(2) $\mathrm{C}_{1, t}=\left(H^{0}+H_{t}\right)\left(1-v n_{t}-h_{t} n_{t}-I_{1 t} n_{t}-I_{2 t}-\theta\right)$.

Old age consumption: is similarly constrained by the parent's accumulated savings at the old-age, retirement phase. We model the latter in the form of defined-benefits PAYG social security system financed by premiums levied on young adults, and is balanced at all periods. This "forced savings" avoids the need to introduce savings as a distinct choice variable, although we could also allow for voluntary savings via a national annuities market with a given rate of interest. Old age income is thus provided by defined benefits per surviving old adult: $\mathrm{S}_{\mathrm{t}+1}$. Since the system is balanced, the expected defined benefits must equal expected premiums, levied via a tax, $\theta$, on the young worker's income: $\pi_{2, t} S_{t^{+1}}=\pi_{1, t} n_{t} \theta\left(H^{0}+H_{t+1}\right)$. Thus, in equilibrium,

(3) $C_{2, t+1} \equiv S_{t+1}=\left(\pi_{1, t} / \pi_{2, t}\right) n_{t} \theta\left(H^{0}+H_{t+1}\right)$,

and young parents take the defined benefits value $S_{t+1}$ as given.

The altruism function: Parents obtain altruistic or "companionship" benefits they derive vicariously from the quantity and productive capacities they helped generate in their surviving children via their investments in them. ${ }^{5}$ Companionship benefits are thus given by:

(4) $C_{3, t+1}=B\left(\pi_{1, t} n_{t}\right)^{\beta}\left(H^{0}+H_{t+1}\right)$,

where $\beta>1$ is needed to get interior solutions in the quantity and quality of children, $n_{t}$ and $H_{t+1}$. 
The expected life-time utility function: We specify the utility operator associated with each "consumption" component as an iso-elastic, or constant relative risk aversion function and assume that all consumption components are strongly-additive. Expected utility is then given by:

(5) $E U_{t}\left(H^{0}+H_{t}\right)=[1 /(1-\sigma)]\left[C_{1, t}^{1-\sigma}-1\right]+\delta \pi_{2, t}\left\{[1 /(1-\sigma)]\left[C_{2, t+1}{ }^{1-\sigma}-1\right]+[1 /(1-\sigma)]\left[C_{3, t+1}{ }^{1-\sigma}-1\right]\right\}$, with $\pi_{1}$, and $\pi_{2}$ denoting the probabilities of survival to adulthood and old age. In the baseline model we focus on health spending exclusively as a means of influencing these probabilities.

\section{The Life-Protection Production Functions.}

We specify the phase-specific $(j)$ life-protection functions controlling children's $(t+1)$ and own $(t)$ generations' survival probabilities as hyperbolic and concave production functions: ${ }^{6}$ (6) $\pi_{j}\left(I_{j}, H_{t}\right)=\Gamma_{j H}\left(H_{t}\right)-D_{j}\left(k_{j}+I_{j}\right)^{-\varepsilon_{j}}$, where

(6a) $\Gamma_{j H}\left(H_{t}\right)=\Gamma_{j H}^{U}\left(1-\eta_{0 j} H_{t}^{-\eta_{j}}\right)$

(6b) $k_{j}=\left[\left(\Gamma_{j H}\left(H_{t}\right)-\Gamma_{j L}\right) / D_{j}\right]^{-1 / \varepsilon_{j}}$,

with $\Gamma_{j H}\left(H_{t}=\infty\right)=\Gamma_{j H}^{U}, \pi_{j}\left(I_{j}=0\right)=\Gamma_{j L}$, and $\pi_{j}\left(I_{j}=\infty, H_{t}\right)=\Gamma_{j H}\left(H_{t}\right)$. This specification is designed to capture the role of the main inputs governing the production of health as life protection, along with the necessary constraints that need to be imposed on health outcomes measured as survival probabilities. The direct inputs are the shares of full income, $I_{1}$ and $I_{2}$, the representative parent's generation spends to protect their child's and their own survival to the next phase of life which include personal, medical and scholarly inputs such as exercise, diet, medical check-ups, related medical products and services, and health-related research and development. In equation (6) these inputs raise the survival probabilities by lowering the degree to which the initial levels of these probabilities can potentially deteriorate, or "depreciate" over the next phase of life, $D_{j}\left(k_{j}+I_{j}\right)^{-\varepsilon_{j}}$. 
Consistent with the empirical literature on health production, equation (6) also recognizes, however, the role of general education as an indirect input which enhances the initial level of survival probability at which a person enters into a new phase of life, and thereby both the average and the marginal productivity of any direct inputs expanded on life-protection. ${ }^{7}$ Both inputs are subject to diminishing marginal productivity within a given period, or phase of life. In equation (6), $\eta_{0 j}>0, \eta_{j}>0$, and $\varepsilon_{j}>0$ assure the concavity of both of its components.

Furthermore, the production function must also constrain the output of these inputs $\pi_{j}\left(I_{j}, H_{t}\right)$ not to exceed or fall short of upper and lower bounds. In equation (6a) this requires that even the highest levels of individual general education (predetermined by parents) cannot raise survival probabilities above some upper bound $\Gamma_{j H}^{U}<1$ or fall below a lower bound $f_{j} \Gamma_{j H}^{U}>0$ at any given level of $I_{j}$, both reflecting the state of the arts in health sciences. An example of shifts in $\Gamma_{j H}^{U}$ is breakthroughs in the treatment of Leukemia in children and adolescents which have raised survival rates from 3\% in 1964 to $92 \%$ in 2003-2009 (see LLS facts 2013). Stated formally, for given $I_{j}, \Gamma_{j H}\left(H_{t}=\infty\right)=\Gamma_{j H}^{U}$ and $\Gamma_{j H}\left[H_{t}=H(0)\right]=f_{j} \Gamma_{j H}^{U}$, where $f_{j}$ denotes the fraction of $\Gamma_{j H}^{U}$ that is attainable at the lowest level of one's predetermined knowledge. The magnitude of $f_{j}$, in turn, is reflected in the value of the coefficient $\eta_{0}$ in equation (6a), which must equal by definition to $\eta_{0}=\left[1-f_{j}\right] /\left[H(0)^{-\eta_{1}}\right]$. By the same token, life protection inputs cannot produce survival probabilities exceeding an upper bound or fall short of a lower bound. Stated formally, $\pi_{j}\left(I_{j}=0 \mid H_{t}\right)=\pi_{j L}>0 ; \pi_{j}\left(I_{j} \rightarrow \infty \mid H_{t}\right)=\Gamma_{j H}\left(H_{t}\right) \leq 1$, and $\pi_{j L}<\Gamma_{j H} U$.

Life expectancy and the GDP-share of health spending SHS: Before moving to optimization analysis we define two concepts which play a crucial role in our simulation analysis as well. In our overlapping generation model period life expectancy (LE) is defined as

(6c) $L E_{t}=T+\pi_{1, t} T+\pi_{1, t} \pi_{2, t} T=\left(1+\pi_{1, t}+\pi_{1, t} \pi, 2 t\right) T$, 
where $\mathrm{T}$ is the length of each phase of life ${ }^{8}$. The full-income share of health expenditure, or $\operatorname{SHS}(\Omega)$, in turn, is defined as $\Omega_{t}=n_{t} I_{1 t}+I_{2 t}$.

\section{Optimization Analysis}

Parents maximize their lifetime utility in equation (5) with respect to our 4 control variables: $n_{t}, h_{t}$, and $I_{j t}(\mathrm{j}=1,2)$, subject to equations (1)-(6). The first-order conditions for interior solutions equalize the marginal rates of substitution between future and present consumption and the discounted gross return on investments in children as follows:

(7) $\left(C_{2, t+1} / C_{1, t}\right)^{\sigma}=\delta R_{n}^{*}, \quad$ where

$R_{n} * \equiv B \pi_{1}^{\beta} \pi_{2} \beta\left(n_{t}\right)^{\beta-1}\left(H^{0}+H_{\mathrm{t}+1}\right)\left(C_{2, t+1} / C_{3, t+1}\right)^{\sigma} /\left[\left(H^{0}+H_{\mathrm{t}}\right)\left(v+h+I_{1, t}\right)\right]$

(8) $\left(C_{2, t+1} / C_{1, t}\right)^{\sigma}=\delta R_{h}^{*}, \quad$ where

$R_{h}^{*}=A \pi_{1}^{\beta} \pi_{2} B\left(n_{t}\right)^{\beta-1}\left(C_{2, t+1} / C_{3, t+1}\right)^{\sigma}$

(9) $\left(C_{2, t+1} / C_{1, t}\right)^{\sigma}=\delta R_{I_{1, t}}^{*}$, where

$R^{*}{ }_{1, t}=\pi_{1}{ }^{\prime} \pi_{l}^{\beta-1} \pi_{2} B \beta n_{t}^{\beta-1}\left[\left(H^{0}+H_{t+1}\right) /\left(H^{0}+H_{\mathrm{t}}\right)\right]\left[\left(C_{2, t+1} / C_{3, t+1}\right)\right]^{\sigma}$.

(10) $\left(\mathrm{C}_{2, \mathrm{t}+1} / \mathrm{C}_{1, \mathrm{t}}\right)^{\sigma}=\delta R_{I_{2, t}}^{*} \quad$ where

$R_{I_{2, t}}^{*}=\pi_{2}^{\prime}\left[U_{t+l}(2)\right] /\left[C_{2, t+l}^{-\sigma}\left(H^{0}+H_{\mathrm{t}}\right)\right]$, and

$\mathrm{U}_{\mathrm{t}+1}(2) \equiv\left\{[1 /(1-\sigma)]\left[C_{2, t+1}^{1-\sigma}-1\right]+[1 /(1-\sigma)]\left[C_{3, t+1}^{1-\sigma}-1\right]\right\}$

In equilibrium, $R_{n}^{*}=R_{h}^{*}$. This produces a closed-form solution for $h_{t}{ }^{*}$ - one of our key results:

(8a) $h_{t}^{*}=\left[\left(v+I_{1, t}\right) /(\beta-1)\right]-\left[\beta H^{0} / A(\beta-1)\left(H^{0}+H_{t}\right)\right]$.

Similarly, in equilibrium $R_{I_{1, t}}^{*}=R_{h} *$. We can thus solve for the optimal value of $I_{1, t}$ from

(9a) $\left[1 / \pi_{1}{ }^{\prime}\left(I_{1, t}{ }^{*}\right)\right]=\left[\beta\left(H^{0}+H_{t+1}\right)\right] /\left[A \pi_{1}\left(H^{0}+H_{t}\right)\right]=\left(\beta / A \pi_{1}\right)\left\{\mathrm{A} h_{t}+\left[H^{0} /\left(H^{0}+H_{t}\right)\right]\right\}$ where $\pi_{1}^{\prime}=\varepsilon_{1} D_{1}\left(k_{1}+I_{1}\right)^{-\left(\varepsilon_{1}+1\right)}$ from equation (6). 
Proposition 1: Optimal investment in the probability of survival from young age to adulthood $\left(I_{1, t}{ }^{*}\right)$ will directly increase the steady-state rate of investment in human capital $h_{t}{ }^{*}$, thus the corresponding per capita income growth rate, and vice versa.

By (8a) the steady-state income growth rate $A h^{*}=\left(1+g^{*}\right)=A\left[\left(v+I_{1} *\right) /(\beta-1)\right]$, while being independent of any other endogenous variables, is monotonically related to the rate of investment in children's survival to adulthood. Similarly, equation (9a) implies that the steady state level of investment in children's life protection $\left[\pi_{1}{ }^{*} / \pi_{l}{ }^{\prime}\left(I_{1, t}{ }^{*}\right)\right]=\beta h^{*}$ is monotonically related just to investment in knowledge as an endogenous variable. These optimality conditions expose two basic principles linking the two components of human capital as a productive asset: the greater the investment in survival to adulthood $(v+h)$ - the period in which returns to productive knowledge (education) accrue - the greater is the incentive to invest in that knowledge. By the same token, the larger the investment in productive knowledge, the greater is the incentive to protect the resulting asset's viability (health).

Proposition 2: Investment in health that raises the parent's probability of survival from adulthood to old age $\left(I_{2, t}\right)$ is not expected to have any growth effects. Its optimal value is motivated by the wealth-driven "private value of life saving", as assessed by the parent.

Stated in terms of the shadow price of life protection of oneself, equation (10) becomes:

$$
\text { (10a) } 1 / \pi_{2}^{\prime}=\delta\left[U_{t+l}(2)\right] /\left[C_{1, t}^{-\sigma}\left(H^{0}+H_{\mathrm{t}}\right)\right] \text {, }
$$

where $\pi_{2}^{\prime}=\varepsilon_{2} D_{2}\left(k_{2}+I_{2}\right)^{-\left(\varepsilon_{2}+1\right)}$ from equation (6). Equations (9a) and (10a) require that the marginal costs of investing in the life protection of child and self would be equal to their marginal returns. Multiplying (9a) and (10a) by production capacity or full income, $\left(H^{0}+H_{\mathrm{t}}\right)$, the LHS becomes the marginal cost of the last dollar spent on self-protection and the RHS denotes the "shadow price of life protection". The RHS of equation (10a) would then also 
represent the standard definition of the "private value of own life saving" as perceived by the parent at adulthood: the numerator denotes the discounted utility from living to old age, while the denominator denotes the marginal utility of income for the young parent. ${ }^{9}$

\section{Equilibrium Solutions}

The optimality conditions in equations (7)-(10) represent a system of second-order simultaneous difference equations, so no analytical solutions can be obtained. The dynamic system we solve for via numerical analysis has been partly derived in previous studies (EL 1991 and EK 2007) so we shall here point out just its basic properties. In earlier studies the focus was on the existence of two stable steady states solutions: a "stagnant equilibrium", in which human capital and income per agent remain constant, and a "growth equilibrium" in which both rise without limit. Takeoff from stagnation to growth equilibrium must raise the share of productive capital parents invest in educating their children above the critical level $\mathrm{Ah}^{*}>1$ in equation (2). But trigger parameters, which by our model may include upward shifts in the technology of life and health protection as well as learning, can also shift the economy from one growth-equilibrium to another by raising the steady-state level of investment in knowledge capital, $\mathrm{h}$ * (see section III).

The sufficient conditions that assure the existence and stability of such steady states stagnant or growth equilibrium - include the concavity of the utility and life-protection production functions, as well as the parametric restrictions that allow for interior solutions for the system's control variables, $I_{j t}, n_{t}$ and $h_{t}: \beta(1-\sigma)<1, \beta>1,1 / 2 \leq \sigma<1$, and $\eta_{j}, \varepsilon_{j}>0$.

\section{Illustrating the Solution of the Baseline Model through Numerical Analysis}

To illustrate the equilibrium properties of the baseline model, we need to solve it numerically. The parameters we use in this illustration are adopted, however, from the calibrated simulations of the extended model in which the baseline model is nested. This has the advantage 
of linking the analytically simplified baseline model with the extended model in which health spending serves also as a means of producing health maintenance or "remedial care" to smooth out fluctuation in health status due to incidents of morbidity within a given phase of life. This way, the dynamic solutions of the two models become comparable within a unified system. ${ }^{10}$

General solution - there is a Steady State: The dynamic solutions for the variables governing optimal investment in the health and life protection of children, $I_{1}$, as well as children's education, $h$, and thus the rate of knowledge-capital formation and per-capita income growth, $(1+g)$, are the same for the baseline and the extended model, as indicated by proposition 1. We therefore plot them in Figure 3. In Figure 4 we also present the dynamic solutions for other key endogenous variables in the baseline model along with their counterparts in the extended model, notably the rate of fertility, population aging, and the share of health spending in full income, SHS. As these figures indicate, the dynamic system emerging from our calibrated simulations in the following section, which are targeted to link with observed empirical data on key control variables, suggests that the US is in a growth equilibrium regime. This contains the response to the first question we set out to explore: there is, in principle, a balanced and stable steady state solution for our model in which the "control variables" of the model - the shares of the representative agent's productive capacity that are devoted to bear, educate, and protect the lives of children and adults - reach a constant level asymptotically while the "state variables" representing human capital formation, income, and consumption (including "altruistic consumption") grow without bound. The shadow prices of life-protection and population aging also reach a constant level asymptotically.

In particular, as both Figure 3-1.D and 4.C indicate, our key variable of interest, the share of production capacity devoted to life-protection, does have an upper bound. The simulation 
produces an equilibrium solution for this share, which stands for the full-income share of health spending. In the baseline model, the steady-state value of this variable, $\Omega(t)=n_{t} I_{1, t}+I_{2, t}$, is estimated to be $18.28 \%$ of production capacity (but see section III). The linkage with GDP, however, is a matter of interpretation: if we interpret the share of time spent by the representative agent on life-protection as "protective health care services", reflected by doctors and researchers, then the solution for $\Omega$ would mimic the share of SHS in "market income", or GDP. If preventive health care inputs include individual time spent outside the labor market, then $\Omega$ would include opportunity costs of leisure time, which is not captured in GDP, but then $\Omega$ would be a share of "full income", rather than GDP.

What brings about the steady state solution? The "secret" lies in the dynamic behavior of the shadow price of investment in life protection $I_{1}$ and $I_{2}$ relative to consumption. This can be seen from equations (9a) and (10a). The equilibrium rates of investment in life protection for children and adults are set in any given period when the shadow price of life protection, or the parent's assessment of the value of life saving, measured in real terms (VLS*), is equalized with that of health investment, $M C \pi_{\mathrm{j}}$. As (9a) and (10a) indicate, optimal VLS* is rising over time by the force of increasing lifetime income, or wealth, due to persistent human capital formation. The latter, in turn, raises the derived demand for life-protection $I_{1}, I_{2}$, and thus the share of health spending in full income $\Omega(t)=n_{t} I_{I t}+I_{2, t}$, despite the drop in fertility $(n)$ in the early part of the transition to a steady state. But diminishing returns to life protection, which raise its shadow price relative to consumption, slows down the rise in life protection spending $\Omega(t)$ and eventually brings it to a halt.

This can be seen clearly if we first ignore the role of general education as an efficiency parameter in equation (6). But even if we allow for the role of the latter as capturing continuous 
improvements in medical knowledge, it has a limited force in equation (6), since $\left(1-\eta_{0 j} H_{t}^{-\eta_{j}}\right)$ has a limit of 1 when $H_{t}$ approaches an infinite value. The accumulation of knowledge capital mainly extends the period over which optimal $\mathrm{VLS}_{\mathrm{j}}{ }^{*}$ keeps rising. It is ultimately the tension between the ever rising VLS* and the diminishing returns to investment in life protection which brings about a predictable steady-state share of income that is spent on life and health protection.

Equation (6) still allows, however, for the possibility that life expectancy continue to rise without limit. This could occur as a result of exogenous breakthroughs in life-saving technology, which are captured by the coefficients $\Gamma_{j H}^{U}$ and $D_{j}$ in equation (6). Since they occur discretely, such shocks are not subject to diminishing returns, although their impact may wear off over time.

\section{The Extended Model}

The baseline model treats spending on health and life protection as being motivated strictly by demand for quantity of life, i.e., survival to the next phase of life. Such spending is prospective - an investment in future health. But some health spending can also affect well-being contemporaneously by smoothing out the effects of morbidity on healthy time via health maintenance and remedial care spending within a given phase of life. ${ }^{11}$ Morbidity in a given phase, however, is generally inversely related to the conditional probability of survival to that phase. In the extended model we therefore model healthy time as a function of both effective health maintenance at phase $\mathrm{j}$ and the probability of survival to that phase, and treat the health benefits obtained from healthy time as a good complementary to ordinary consumption. ${ }^{12}$ By the structure of the model, such remedial care thus becomes the dominant component of health spending at old age, where there is no allowance for investment in survival to a future phase. This makes it important to incorporate remedial care, $M_{j}$, into our extended prototype model. 


\section{Adding Health as Consumption and Health Spending as Remedial Medical Care}

Formally, we distinguish the flow of health benefits $H B_{j}$ consumed by a representative parent in phase $\mathrm{j}$ from ordinary consumption, here named $X_{j} . H B_{j}$ is assumed to be derived from the amount of healthy time within phase $\mathrm{j}, H T_{j}$, which can be lost due to incidences of morbidity, but which can be regained through health maintenance and remedial medical care at adulthood and old age, $M_{j}{ }^{13}$ The frequency of morbidity can be linked to the predetermined probability of survival to $\mathrm{j}, \pi_{j}$. The full linkage between $H B_{j}\left(M_{j}, \pi_{j}\right)$ and its determinants is spelled out below.

To account for the degree of complementarity between the pair of goods $H B_{j}$ and $X_{j}$, the utility of consumption of generation $t$ at phase $j=1,2$ is specified as a CES function:

(11) $\mathrm{U}\left(H B_{j, t}, X_{j, t}\right)=[1 /(1-\sigma)]\left[\mathrm{N}\left(H B_{j, t}{ }^{\rho}+X_{j, t}{ }^{\rho}\right)^{(1-\sigma) / \rho}-1\right]$

where $\rho$ dictates the extent to which $H B$ and $X$ are substitutes or complements ( $\rho=1$ or $-\infty$ imply they are perfect substitutes or complements, respectively), and $\mathrm{N}$ is a normalization factor. ${ }^{14}$ While $X_{j}$ is purchasable at a market price (normalized at 1), however, the flow of health benefits $H B\left(M_{j}, \pi_{\mathrm{j}}\right)$ must be derived from a production process and related transformations. First, $H T_{j, t}$ must be converted to nominal health benefits via:

(11a) $H B_{j, t} \equiv c_{j}^{e} H T_{j, t}$,

where $c_{j}^{e}$ is the unit value of $H T_{j}$ in nominal terms. ${ }^{15}$ Second, the prospect of morbidity losses (L) can be mitigated through remedial care and effective health maintenance by the representative agents of generation $t$ at adulthood $(\mathrm{j}=1)$ and of generation $\mathrm{t}-1$ at old age $(\mathrm{j}=2)$, which are enhanced by the general level of education at time $\mathrm{t}, H_{t} \cdot{ }^{16}$ The production function of healthy time can thus be stated symmetrically to that in equation (6) as follows:

$$
H T\left(m_{j t}, H_{t}, \pi_{j}\right)=H T_{H}\left(H_{t}\right)-D_{j m}\left(k_{j m}+m_{j t}\right)^{-\varepsilon_{j m}}>0, \text { where }
$$

$$
H T_{H}\left(H_{t}\right)=H T_{H}^{U}\left(1-\eta_{0 m} H_{t}^{-\eta_{m}}\right)>0
$$


(12b) $H T\left(m_{j t}=0, H_{t}, \pi_{j}\right)=H T_{H}\left(H_{t}\right)-L\left(\pi_{j}\right)$,

(12c) $k_{j m}=\left(L_{j} / D_{j m}\right)^{-1 / \varepsilon_{j m}}>0$,

and $m_{j t} \equiv M_{j} / T C_{j}$ denotes the share of total consumption outlays $\left(T C_{j}\right)$ devoted to remedial medical spending, $M_{j}$.

The idea behind equation (12) is that the representative agent in generation $\mathrm{t}$ enters a given phase of life, $\mathrm{j}$, with a level of morbidity-free healthy time which varies as a function of the agent's knowledge capital and spending on remedial care. As a function of knowledge capital $\left(H_{t}\right)$, equation (12a) indicates that $H T_{H}$ cannot exceed an upper limit $H T_{H}^{U}$ (as $\left.\mathrm{H}_{\mathrm{t}} \rightarrow \infty\right)$, or fall below a lower limit $H T_{H}\left(H_{t}=H_{0}\right)=f_{m} H T_{H}{ }^{U}$, with $H_{0}>0$ denoting an initial $H_{t}$ level, and $f_{m}$ is a positive fraction of $H T_{H}{ }^{U}$, which determines the value of the coefficient $\eta_{0 m}$ in equation (12a). The prospect of morbidity, however, can inflict a loss of healthy time, which we link below with the agent's probability of survival to phase $\mathrm{j}$. In the absence of any remedial care $(m=0)$, the maximal potential loss of healthy time, is thus given by $L\left(\pi_{\mathrm{j}}\right)$ in equation $(12 \mathrm{~b})$. The loss can be limited, however, by remedial care spending as indicated by equation (12), subject to the following upper and lower bounds: $H T\left(m_{j t}=\infty \mid H_{t}\right)=H T\left(H_{t}\right)$, and $H T\left(m_{j t}=0 \mid H_{t}\right)=H T\left(H_{t}\right)-L\left(\pi_{j}\right)=$ $H T\left(H_{t}\right)-D\left(k_{j m}\right)^{-\varepsilon_{j m}}$. The latter equality constrains the level of $k_{j m}$ as stated in equation (12c).

But the link between the maximum potential time loss to morbidity $L\left(\pi_{\mathrm{j}}\right)$ and survival risks needs to be further spelled out. In a given phase of life, $L_{j}$ depends on both the probability of morbidity, $\pi_{m j}$, and its severity, or frequency. It is plausible to expect a strong link between $\pi_{m j}$, and the predetermined probability of survival to phase $\mathrm{j}, \pi_{j}$. While a higher $\pi_{j}$ implies that a surviving agent enters phase $\mathrm{j}$ healthier, thus with a lower risk of morbidity, however, the frequency of morbidity would be higher for those entering phase $\mathrm{j}$ less healthy - partly because 
they are older on average over time - and thus with a higher risk of non-survival, $\left(1-\pi_{j}\right)$. The latter is especially potent at old age. ${ }^{17} \mathrm{We}$ account for these opposing effects as follows:

$$
L_{j}\left(\pi_{j}\right)=L_{0 j}\left(1-\pi_{j}\right)^{\phi_{j}} \pi_{j}^{\gamma_{j}}
$$

Equations $(11 \mathrm{a}-12 \mathrm{~d})$ thus link $H B_{j}\left(M_{j}, \pi_{j}\right)$ with its direct $\left(M_{j}\right)$ and predetermined $\left(\pi_{j}\right)$ determinants. Also, the "budget constraint" limiting parental total spending on the inputs producing the consumption goods $H B_{j, t}$ and $X_{j, t}$ can now be stated as (13) $M_{j, t}+X_{j, t}=T C_{j, t}^{0}$

for any level of non-consumption spending given by the RHS of equations (2) and (3).

\section{Optimization analysis in the Extended Model}

The young parent's optimization problem can be described heuristically as a two-stage process. In the second stage, we maximize the utility function (11) with respect to the consumption inputs $M_{j}$ and $X_{j}$, subject to the budget constraint (13), and given values of $\pi_{\mathrm{j}}$. The solution produces the following indirect utility function for generation $\mathrm{t}$ :

(11b) $V\left(T C_{j}\right) \equiv U\left(H B_{j}\left(M_{j}^{*}\right), X_{j}^{*}\right)=[1 /(1-\sigma)]\left[\mathrm{N}\left(H B_{j}{ }^{\rho}+X_{j}^{*}{ }^{\rho}\right)^{(1-\sigma) / \rho}-1\right]$.

Omitting subscripts, note that by equation (11b) the marginal utilities a representative parent derives from remedial care and ordinary consumption spending must be equal, or $\partial \mathrm{U} / \partial \mathrm{M}=(\partial \mathrm{U} / \partial \mathrm{HB})(\partial \mathrm{HB} / \partial \mathrm{X})=\partial \mathrm{U} / \partial \mathrm{X}$. This condition allows us to solve for the optimal ratio of health benefit to ordinary consumption in producing any utility level:

(14) $\partial \mathrm{HB} / \partial \mathrm{M}=\left(\mathrm{HB}^{*} / \mathrm{X}^{*}\right)^{1-\rho}$.

The value of $M^{*}$ can then be extricated from equation (14) using equations (11a-12d) as follows:

(14a) $M^{*}=\left\{\left[\left(H B^{*} / X^{*}\right)^{1-\rho}\left(T C / c^{e}\right)\left(1 / D_{m} \varepsilon_{m}\right)\right]^{-1 /\left(\varepsilon_{m}+1\right)}-k_{m}\right\} T C$, where $X^{*}=T C-M^{*}$ by (13). 
In the first stage maximization process we can now insert the indirect utility function $V(T C)=U\left(H B^{*}, X^{*}\right)$ into the life-time utility function in equation (5) and proceed with maximizing the latter with respect to the control variables $n, h, I_{1}$ and $I_{2}$ as in the baseline model: (5a) $E U^{\prime}{ }_{t}\left(H^{0}+H_{t}\right)=\mathrm{V}\left(T C^{*}{ }_{1, t}\right)+\delta \pi_{2}\left\{\mathrm{~V}\left(T C^{*}{ }_{2, t+1}\right)+[1 /(1-\sigma)]\left[C_{3, t+1}{ }^{l-\sigma}-1\right]\right\}$. The optimality conditions become:

$$
\begin{aligned}
&(15) \quad M U\left(T C_{1, t}\right) / M U\left(T C_{2, t+1}\right)=\delta R_{n}^{*} ; \quad \text { where } M U \equiv \partial V(T C) / \partial T C \\
& R_{n}{ }^{*} \equiv B \pi_{1} \pi_{2} \beta\left(n_{t}\right)^{\beta-1}\left(H^{0}+H_{t}\right) /\left\{M U\left(T C_{2, t+1}\right) C_{3, t+1}{ }^{\sigma} *\left[\left(H^{0}+H_{t}\right)\left(v+h+I_{1, t}\right)\right]\right\} \\
&(16) \quad M U\left(T C_{1, t}\right) / M U\left(T C_{2, t+1}\right)=\delta R_{h}^{*} ; \\
& R_{h}^{*}=\left.A \pi_{1}^{\beta} \pi_{2} B\left(n_{t}\right)^{\beta-1} / M U\left(T C_{2, t+1}\right)\left(C_{3, t+1}\right)^{\sigma}\right] \\
&(17) \quad M U\left(T C_{1, t}\right) / M U\left(T C_{2, t+1}\right)=\delta R^{*}{ }_{I I ;} \\
& R_{I_{1, t}=}^{*} \pi_{1}^{\beta-1} \pi_{2} B \beta n_{t}^{\beta-1}\left[\left(H^{0}+H_{t+1}\right) /\left(H^{0}+H_{t}\right)\right]\left[M U\left(T C_{2, t+1}\right)\left(C_{3, t+1}\right)^{\sigma}\right] \\
&(18) \quad M U\left(T C_{1, t}\right) / M U\left(T C_{2, t+1}\right)=\delta \mathrm{R}^{*}{ }_{\mathrm{l} 2 ;} \\
& R^{*}{ }_{I_{2, t}}= {\left[\mathrm{U}_{\mathrm{t}+1}(2)\right] /\left[M U\left(T C_{2, t+1}\right)\left(H^{0}+H_{t}\right)\right] ; } \\
& \text { where } \mathrm{U}_{\mathrm{t}+1}(2) \equiv\left\{V\left(T C_{2, t+1}\right)+[1 /(1-\sigma)]\left[C_{3, t+1}{ }^{1-\sigma}-1\right]\right\} .
\end{aligned}
$$

It is straightforward to see that by combining equations (15) and (16) we obtain the same solutions given by equations (8a) and (9a). This implies that the optimal investments in knowledge capital $(h)$ and children's life protection $\left(I_{I}\right)$, hence Proposition 1, are unaffected by remedial care. Not only do the steady state values of $h$ and $I_{1}$ stay the same, but also their transitional paths remain identical in the baseline and extended models. Hence:

Proposition 3: Health maintenance and remedial medical care at adulthood and old age can raise the quality of life by generating direct health benefits and possible indirect increases in life protection. They have no impact on economic growth, essentially because they do not affect 
the incentive to invest in children's knowledge capital, which, by our prototype model, drives human capital formation and growth.

Note, however, that remedial care spending on children, which is subsumed under spending on the latter's well-being and life protection $\left(v n_{t}+I_{l t} n_{t}\right)$, does contribute to growth by proposition 1 .

\section{Simulation Methodology}

The numerical methodology we use to solve our extended model and its nested baseline portion must account for the dynamic evolution of SHS in GDP and all its simultaneously determined variables. These include the components of health care spending associated with life protection and remedial care over different phases of the life cycle, as well as human capital formation, per-capita income growth, and the population dynamics resulting from the evolution of fertility and survival probabilities and hence life expectancy and the aging of the population across generations at adulthood. To account for the combined tasks, the numerical analysis involves the computation of optimal solutions for all key control and state variables, based on the optimality conditions governing the choices of the representative parent in a given generation (equations 15-18), and then passing the relevant solution values on to the overlapping generation to derive the next representative parent's solutions for the corresponding control and state variables that are conditional on those of the previous generation.

In the extended model, unlike the baseline model, the solution to the system involves a twostep optimization process to account for optimal values of remedial care inputs (M) and ordinary consumption $(\mathrm{X})$, given the budget constraint on total consumption spending as set by the optimal values of all other control variables entering equations (2) and (3). The full-income share of health spending (SHS) now includes the remedial care component as well. Note that since the choice of remedial care at old age is actually done by the previous (grandparents') generation, 
the relevant remedial care decision variables are $M_{1, t}$ and $M_{2, t-1}$. SHS thus becomes: (19) $\Omega_{\mathrm{t}}=\mathrm{n}_{\mathrm{t}} \mathrm{I}_{1 \mathrm{t}}+\mathrm{I}_{2 \mathrm{t}}+\mathrm{M}_{1 \mathrm{t}} /\left(\mathrm{H}_{\mathrm{t}}+\mathrm{H}^{0}\right)+\mathrm{m}_{2, \mathrm{t}-\mathrm{1}} \theta .^{18}$

\section{A. Calibration}

We calibrate the model's parameters using US data and consensus estimates. Based on Gruber (2006), we set the inter-temporal elasticity of substitution at 2 (or the coefficient of risk aversion at $\sigma=0.5$ ). Consistent with many studies, we take the time preference parameter to be $1.5 \%$, thus setting our discount factor at $\delta=(1 / 1.015)^{30}$. The unit cost of raising children, $v$, is calculated from Table 5 in Juster and Stafford (1991). The table reports the average fraction of time allocated to childcare to be $6.29 \%$. Since average total fertility rate was 2.1 in the period $1970-1980, v$ is estimated to be $3.0 \%(=6.29 / 2.1)$ of full income (c.f. EK 2007). To approximate the lower bounds of survival probabilities $\Gamma_{\mathrm{jL}}$, we have searched for the earliest historical data reported for the US. The values we selected -0.67 for $\Gamma_{1 \mathrm{~L}}$ and 0.37 for $\Gamma_{2 \mathrm{~L}}-$ are taken from the historical life tables for the US in 1850 (Haines, 1998).

The remaining parameters of the model, $A, \beta, B, \theta, D_{j}, \varepsilon_{j}, \eta_{j}, \Gamma_{j H}^{U}, f_{j}, \rho, N, c_{j}^{e}, L_{0 j}, \gamma_{j}, \varphi_{j}, H T_{H}^{U}$, $\eta_{m}, D_{m j}, \varepsilon_{m j}$, and $f_{m}$ are then calibrated subject to the optimality conditions for interior solutions, and by requiring that the solutions meet four targets, the first three in the steady state: 1) growth rate of real per-capita income of $1.846 \%$; 2) total fertility rate (TFR) of $2.03 ; 3$ ) a smoothed consumption level for parents over the life-cycle; but 4) the income-share of health spending (SHS) is targeted to be $17.9 \%$ in generation 2 of our numerical simulations.

The first target is designed to match the real average per-capita GDP growth rate in the US from 1970 to 2008, based on Madison (2003) and BEA. Since TFR has exhibited a generally declining secular trend, we have targeted it to match the average TFR over the period 1991-2010, based on National Vital Statistics Reports. Our third target is compatible with data from the 
2010 Consumer Expenditure Survey showing that average consumption of a consumer unit headed by a person in the age groups 35-64 and 65 and older is roughly the same. The fourth target is aimed to match the current SHS in GDP as reported by the Statistical Abstract of the United States (2011). ${ }^{19}$

\section{IV.Simulation Results of the Extended Model}

\section{Basic results}

The extended model's simulation results confirm the principal results derived from the baseline model: an equilibrium steady state exists and is dynamically stable by virtue of the forces controlling the production of both life protection and its maintenance. They also indicate that health maintenance and remedial care, $\mathrm{M}_{\mathrm{j}}$, account for a significant part of total health spending despite the fact that we restrict them in this analysis to contribute pure consumption benefits.

\section{Transitional Paths}

As seen by the shape of the dynamic paths of the model's key control and state variables in Figure 3, our calibrated simulations are successful in producing realistic dynamic paths, or secular trends, of health spending and population aging, along with per-capita income growth. Despite the technical limitations of the model, the calibrated simulations produce numerical solutions for some of the steady state control variables of the model that are of reasonable, although generally understated, orders of magnitude, including fertility, aging, survival probabilities and even life expectancy and SHS, as indicated in Table 1 (see also section V) ${ }^{20}$

The paths indicate that the US has been on a transitional evolution path from some past steady states to a new steady state of growth. The model's limitations do not enable us to pinpoint where the transitional shocks have occurred - these may have taken place in the 1940s 
as a result of medical breakthroughs (a la Acemoglu and Johnson [AJ], 2007, or Hansen, 2013) or in the 1960s via major institutional changes in health financing, or even in the 1970s as a result of improvements in information technology, and they may also reflect residual influences of earlier take-off parameters. The transition paths in Figure 3 do mimic, however, the observed historical trends in key endogenous variables, especially in recent decades.

Indeed, while all the key control and state variables including investments in survival probabilities $I_{1}$ and $I_{2}$, and the overall spending on remedial care, hence SHS, rise monotonically toward their steady state values, fertility (n) shows a declining trend. Also, while remedial care at old age $\left(\mathrm{m}_{2}\right)$ exhibits an increasing trend, essentially due to rising personal wealth and the greater need to maintain good health as longevity rises, remedial care at young adulthood $\left(\mathrm{m}_{1}\right)$, which is much smaller quantitatively by our numerical analysis, falls slightly over time. Furthermore, the speeds at which some variables converge on their steady-state levels are quite different. While fertility, survival from young age to adulthood, $\pi_{1}$, and investment in human capital, $\mathrm{h}$ (and thus the growth rate of per-capita income) already tend to approach their steady state levels, this is not the case for population aging and life expectancy, and especially for SHS and the survival probability to old age, $\pi_{2}$, where the dynamic paths are progressing more slowly toward their asymptotic values.

This pattern generally applies to the baseline model as well: while investment in knowledge capital and life protection, $h$ and $I_{l}$, and thus the probability of survival to adulthood, $\pi_{1}$, and the income growth rate, remain unchanged, confirming proposition 3. However, other control and state variables show changes of varying degrees (see Figure 4). Compared with the baseline model, however, the allowance for remedial care increases markedly the share of health spending in full income ( $\Omega=$ SHS) or GDP, and population aging, caused mainly by a reduction 
in fertility (n), but a much more modest increase in life expectancy due to just a minor rise in life protection at, and survival to, old age $\left(I_{2}{ }^{*}\right.$ and $\left.\pi_{2}{ }^{*}\right)$. The latter is not a surprising result, since remedial care by definition does not affect survival probability.

Since we calibrate the extended model to match the estimated SHS of generation 2 with its current level in the US of $17.9 \%$ of GDP, Fig. 3-1.D can be used to project that the steady-state level of SHS in the stylized economy of the extended model may reach about $21.5 \%$ of full income. This figure is higher than the one implied by the baseline model, as indicated by the dashed path in Fig. 4C- about 18\%. Fig. 3-1.D also allows us to illustrate the hypothetical number of generations it might take the stylized economy of our extended model to reach its steady-state level. Since a literal steady state is achievable only as time goes to infinity, we use 2 measures to determine how long it would take the economy to reach an approximate steady state SHS level. Fig 4C indicates that it would take 4 generations for the economy to reach $95 \%$ of its steady state level. Alternatively, it would also take 4 generations to reach an SHS level at which its rate of change going forward is less than $1 \%$. The corresponding projections based on baseline economy indicate that it would take the economy even longer - 5 generations - to reach a steady state level, starting with the current generation. The implication is that remedial care raises the equilibrium SHS level but lowers the period of transition it may take to reach it, essentially because of the added restraining force of a rising shadow price of remedial care. ${ }^{21}$

\section{Comparative dynamics}

Table 1 presents the qualitative results of the effects of shifts in the calibrated parameters of our model. The comparative dynamic effects are not entirely predictable, as they are affected by feedback and general equilibrium effects as well. We therefore attempt to rationalize the estimated effects in Table 1 on the basis of the direct effects that are exerted by the primary 
economic forces at work: wealth (expected utility) and growth effects, implicit productivity and shadow-price effects, and changes in preferences.

a. Shifts in production parameters generating positive wealth effects, and positive or zero growth effects: These include upward shifts in the productivity of knowledge transfer (A), such as the PC revolution; advances in the life protection of kids $\left(\Gamma_{1 H}{ }^{U}\right)$, such as breakthroughs in the treatment of childhood leukemia and lymphoma that lead to significant increases in the children's survival rates; or increases in the effectiveness of general knowledge capital as an efficiency parameter in life protection $\left(\eta_{1}\right)$. These technological advances increase the optimal investments in children's education and health $\left(h\right.$ and $\left.I_{1}\right)$ and lift up the transition paths of children's survival probability and the steady-state rate of economic growth. The positive wealth effect also raises the demand for survival to old age and for quality of life $\left(\mathrm{HB}_{\mathrm{j}}\right.$ and $\left.\mathrm{X}_{\mathrm{j}}\right)$, and hence for spending on survival to, and remedial care for, old age $\left(\mathrm{I}_{2}\right.$ and $\left.\mathrm{m}_{2}\right)$, which lead to increases in both life expectancy and the GDP share of health spending $(\Omega)$. Since fertility $\left(\mathrm{n}^{*}\right)$ a parental good - also rises, population aging falls as a result. ${ }^{22}$

Upward shifts in the efficiency of general knowledge capital which enhance old-age survival, $\Gamma_{2 H}^{U}$ and $\eta_{2}$, in contrast, generate positive wealth effects but no growth effects by proposition 2. Their effects are generally similar to those of $\Gamma_{1 H}^{U}$ and $\eta_{1}$ except that improvements in the quantity of life are offset by reductions in quality of life $\left(\mathrm{HB}_{\mathrm{j}}\right.$ and $\left.\mathrm{X}_{\mathrm{j}}\right)$.

b. Shifts in production parameters generating negative wealth effects but positive growth effects: These apply to upward shocks in the unit cost of bearing and caring for children. Such shocks raise the marginal cost of the quantity of children relative to investments in their education and life protection. In this case, while $h^{*}, I_{1} *, g^{*}$ and life expectancy (LE) likewise 
increase, fertility $\left(\mathrm{n}^{*}\right)$ declines, which raises population aging (PA). The decline in wealth also lowers investment in, and survival to, old age $\left(I_{2}\right.$, and $\left.\pi_{2}^{*}\right)$, and thus SHS $\left(\Omega^{*}\right)$ as well.

c. Shifts in production parameters generating positive wealth effects, but negative productivity and growth effects: These include the parameters controlling the life-protection of children to adulthood (equation 6). Improvements in life-protective devises that limit the potential deterioration in survival risks, represented by a decline in $D_{l}$ and $\varepsilon_{l}$, raise $\pi_{l}$ at any level of investment in life protection $\left(I_{l}\right)$ but at the same time they reduce the marginal productivity of additional investments in life protection. In equilibrium, the net effect would be a rise in $\pi_{1} *$ and $\pi_{2}^{*}$, and hence in life expectancy, LE, but a reduction in $I_{1} *$ and $I_{2} *$ if the "price" elasticity of the derived-demand for life protection is less than 1. SHS therefore declines. Optimal investment in education, $\mathrm{h}^{*}$, (hence the growth rate, $\mathrm{g}^{*}$ ) and total spending on consumption and remedial care at adulthood also fall in this case. But the positive wealth effect generated by a higher $\pi_{1}^{*}$ raises fertility $\left(n^{*}\right)$ along with life expectancy. Population aging thus falls.

d. Shifts in production parameters generating positive wealth but negative productivity and zero growth effects: A similar analysis to that in item 3 applies when we allow for a downward shift in the parameters $D_{2}$, and (generally) $\varepsilon_{2}$ controlling the life-protection production function (6) at adulthood. Here we generally get an increase in $\pi_{2}$, life expectancy, and fertility, but zero effects on knowledge formation and economic growth and a decline in total consumption spending because of competition between quantity and quality of life.

e. Shifts in parameters governing remedial care production: These include the parameters $D_{m j}, \varepsilon_{m j}, H T_{H}^{U}$ and $\eta_{m}$, in equation (12). The effects of shifts in these parameters at the phase of adulthood (j=1) are similar to those of $\mathrm{D}_{0 \mathrm{j}}, \varepsilon_{\mathrm{j}}$, and $\eta_{\mathrm{j}}$ in equation (6): a reduction in $\mathrm{D}_{\mathrm{m} 1}$ and $\varepsilon_{\mathrm{m} 1}$, and an increase in $H T_{H}{ }^{U}$ and $\eta_{m}$ (reinforcing the role of $\mathrm{H}$ as efficiency parameter) increase 
healthy time, but decrease the marginal productivity of remedial care inputs, $\mathrm{m}_{1}$, as healthy time gets closer to its upper limit. While the resulting wealth effect on $\mathrm{HB}_{1}$ is positive, the shadow "price" effect can dominate it because of the higher marginal costs of the more expensive medical treatment. The net effects, as estimated in Table 1, are higher health benefits and ordinary consumption at adulthood, $H B_{1}{ }^{*}$, and $X_{1}^{*}$, generally offset by lower such benefits at old age, and lower investment in life protection at adulthood $I_{2} *\left(\right.$ hence $\left.\pi_{2} *\right)$ and remedial $\left(m_{1} *\right.$ and $\left.m_{2}^{*}\right)$. Life expectancy, SHS*, and fertility also fall in this case.

Symmetrically, technological improvements in remedial care production at old age, $\mathrm{D}_{\mathrm{m} 2}$, or $\varepsilon_{\mathrm{m} 2}$, generate a tradeoff between $\mathrm{HB}^{*}$ and $X^{*}$ at old age and their counterparts at adulthood. But the effects of these shocks deviate from those of their parametric counterparts at adulthood ( $\mathrm{D}_{\mathrm{m} 1}$, or $\varepsilon_{\mathrm{m} 1}$ ) by actually raising $I_{2}{ }^{*}$, and $\pi_{2}{ }^{*}$, and thus life expectancy. Here, the wealth effect dominates the weaker shadow price effect essentially because the conditional probability of survival from adulthood to old age is significantly lower than that from young age to adulthood.

f. Shifts in preference parameters and social security taxes: Such shifts tend to induce tradeoffs between different expected utility-enhancing variables. A lower $\beta$, has essentially the same effects as a rise in the marginal cost of children's quantity, raising investment in knowledge capital, growth, and life expectancy, as well as consumption, health benefits, and remedial care at adulthood, but reducing optimal fertility $\left(\mathrm{n}^{*}\right)$, and thus increasing population aging. A decrease in the mandated social security $\operatorname{tax}(\theta)$, in contrast, will increase fertility but also raise investment in survival to old age $\left(\mathrm{I}_{2}{ }^{*}\right)$ and life expectancy, as well as conventional consumption spending, remedial medical care, and health benefits at old age at the expense of the latter's counterparts at adulthood. Other parametric effects are less predictable as they are influenced by the parameter magnitudes and by feedback and general-equilibrium effects as well. 


\section{What Are the Major Forces Driving the Expansion in Health Spending?}

Our numerical analysis forecasts the steady-state level of the equilibrium full-income SHS to be about $21.5 \%$. This is in all likelihood an underestimate of the equilibrium rate as a percentage of GDP, because of the limitations of our prototype model which is based on a private economy with a private health system and allows for only three overlapping generations. The model thus abstracts from externalities in health care provision, government subsidies, actuarially unfair health insurance, or related inefficiencies that may have contributed to the expansion of health spending over time. Yet, to the extent that government contribution to health-care through Medicare and Medicaid reflects a social planner's optimal spending in the absence of any externalities, we can use the numerical solutions of the model to identify the major forces which account for the actual level and trend of SHS over time. As pointed out in section II.4, we also take SHS to be an approximation of the GDP-share of health spending on the assumption that both market spending and market income differ from full spending and full income by the same percentage of added opportunity costs of time.

We start with the breakdown of the steady state level of SHS by its four sources in equation (19), as estimated by our simulations. Of the total, investment in life protection at young age $\left(n I_{1}\right)$ and adulthood $\left(I_{2}\right)$ account for $5.52 \%$ and $78.9 \%$, respectively, while remedial medical care at adulthood $\left[M_{1} /\left(H_{t}+H^{0}\right)\right]$ and at old age $\left(m_{2, t-1} \theta\right)$ account for $3.83 \%$ and $11.96 \%$, respectively. Note that the last two items measure total spending on remedial medical care by surviving populations from generation $\mathrm{t}$ and $\mathrm{t}-1$, which reflect the latter's expected survival probabilities, rather than the contribution of surviving representative agents. The latter are much higher as shares of consumption spending at old age $\left(m_{2}=13 \%\right)$ relative to adulthood $\left(m_{l}=2 \%\right)$. 
By this analysis it appears that total investment in all measures of life protection at adulthood $\left(I_{2}\right)$, which range from basic research on life-saving chemical entities to improving survival from potentially fatal diseases, account for the lion's share of the level of SHS, as well as its trend over time. While the fraction of SHS spent on remedial medical care for non-fatal diseases seems modest (the difference in the steady state values of SHS in the extended vs. baseline model, where we shut-off the remedial medical care channel, is only $3.2 \%$ ), lifeprotection spending $\left(I_{1}\right.$ and $\left.I_{2}\right)$ also accounts for remedial medical care in avoiding potentially fatal diseases. Indeed, protective and remedial medical care inputs appear to involve significant interactions by our analysis of comparative dynamics.

The related time trends of these components of SHS $\left(n_{t} I_{1 t}, I_{2 t}\right.$ and the share of remedial care for non-fatal diseases in SHS, $T m_{t}$ in Figure 3.4.B) indicate that the continuing growth in $I_{2 t}$ and $\mathrm{Tm}_{t}$ are also the main drivers of the trend in SHS going forward. As indicated by our optimality conditions and propositions 2 and 3, the trends in all components of SHS over the estimated transition paths to a new steady state can be ascribed largely to the factors contributing to the growth in wealth (see below). Indeed, the "wealth elasticity" of demand for total medical spending by generation 2 (calibrated to match the current value of SHS) is estimated to be 1.108 by our model. ${ }^{23}$ The "wealth elasticities" of demand for total spending on the life protection of children and adults ( $I_{1}$ and $I_{2}$ multiplied by full income) are likewise estimated to be 1.049 and 1.132 respectively. Note, however, that elasticities greater than 1 , which drive the progression of SHS and its components over time, apply only over the transition to a new steady state - they converge to unitary elasticities as SHS approaches its steady-state value.

Table 2 present the responsiveness of the steady state level of SHS to a $10 \%$ upward and downward shifts in the major technological parameters affecting SHS by letting each type of 
shift produce a new steady-state equilibrium SHS level. While the alternative directional changes do not produce identical results (elasticities are somewhat smaller for upward changes, as our model predicts) their order of magnitude produces a robust ranking. The results, recorded in elasticity terms, indicate that the greatest force affecting the equilibrium levels of SHS has been breakthroughs in biological and medical sciences which raise the upper-bound of survival probabilities $-\Gamma_{1 \mathrm{H}}^{\mathrm{U}}$ and $\Gamma_{2 \mathrm{H}}^{\mathrm{U}}$ - and especially the latter. The corresponding elasticities are close to $1 \%$. The second most important factor is the technological breakthroughs in knowledge transfer, which enhance human capital formation and economic growth, which are captured by the shocks in parameter A. These elasticities are also indicative of the major triggers that have produced the observed transitional dynamics in key variables. By the results in Table 2, the observed takeoffs in SHS and in economic growth, for example, may have been produced largely by breakthroughs in treatment of historically fatal diseases, such as blood-cell cancers in the early 1960s, and the hi-tech revolution of the 1970s and early 1980s, respectively.

\section{Some Supporting Empirical Evidence}

One of the key insights offered by our model are the distinct impacts of investments in the life protection of children versus adults, $I_{1, t}$ and $I_{2, t}$. By proposition 1, optimal investment in children's survival to adulthood $\left(\pi_{1}{ }^{*}\right)$ is expected to enhance investment in the knowledge component of human capital, thereby raising the steady-state rate of growth in per-capita income as well. By proposition 2, in contrast, investment in adults' survival to old age is expected to produce personal consumption benefits but no direct effects on growth. Such sharp differences arise in our model because of its simplifying distinction between phases of life that are devoted exclusively to education or work. But the thrust of the two propositions is that survival to the phase of labor-market participation permits fuller use of knowledge acquired at younger ages. 
While we have not pursued an empirical implementation of these propositions in this paper, preliminary evidence developed in EL (1991) using an international panel of 65 countries between 1960 and 1985, indicates that a higher initial probability of survival to adulthood $\left(\pi_{l}\right)$ has a positive and significant effect on the long-term rate of economic growth, measured as the average growth rate of per-capita real GDP from 1960 to 1985. A higher probability of survival to old age, by contrast, was found to have a weaker and insignificant effect on growth. ${ }^{24}$

These results are compatible with propositions 1 and 2. They may also provide new insights into recent studies dealing with the impact of life expectancy on economic growth. Acemoglu and Johnson [AJ] (2007), e.g., identify the 1940s as a period involving shocks in medical innovation, such as increased accessibility of Penicillin and further development of antibiotics, and use these shocks to predict subsequent changes in life expectancy. They then use the predicted changes as instrumental variables to test their effect on concurrent levels of GDP per-capita using an international panel of 75 countries over the period 1940-1980 or 1940-2000. They find a positive but insignificant effect of their life expectancy measure on the level of GDP, but a negative effect on GDP per capita, using OLS and IV regression methods.

AJ do not specify the precise channel through which life expectancy is expected to affect changes in the level of GDP per-capita. In an interesting recent study published in this journal, Hansen (2013) addresses this issue. He explores this issue using a somewhat smaller international panel data over a similar time period by regressing separately the level of GDP percapita and the level of a Mincerian measure of human capital per-capita (comprising both average years of schooling and average work experience) on life expectancy at birth 20 years earlier to see if the latter's effect on growth is consistent with its effect on education. His results indicate the existence of positive and significant effects of life expectancy at birth on subsequent 
educational attainments. ${ }^{25}$ But the effect of life expectancy on the level of GDP per-capita remains negative, albeit mainly insignificant, in his analysis as well.

Our model offers an alternative explanation for these findings. First, propositions 1 and 2 address the impact of investment in knowledge capital (education) on the long-term rate of economic growth. Both AJ and Hansen specify GDP levels as the dependent variables and "stock" measures of either life expectancy or educational attainment as explanatory variables. An alternative specification of these two variables as investment flows has been shown to yield results that are more compatible with a positive impact of education on the long-term rate of economic growth (see Ehrlich, 2007, section 6.3). More importantly, our analysis suggests that investment in life protection at young age and survival to adulthood, not life expectancy at birth, determines the long-term GDP growth rates. In recent decades, however, changes in life expectancy may have come about mainly from an increase in survival probabilities from adulthood to old age, and proposition 1 indicates that these survival probabilities may not have a significant effect on investment in education or the economy's steady state growth rate. Indeed, some shocks in medical innovations may even lower the growth in GDP in the long term, as indicated by our comparative dynamics analysis in part IV, section 3.c. ${ }^{26}$

\section{Conclusion}

Like Hall and Jones [HJ] (2007), we view the rising share of health spending (SHS) in the economy as driven by consumer demand in a competitive economy setting. They view the continuous increase in SHS as driven by rising per-capita wealth and a larger than unitary income elasticity of demand. We attempt to take a further step, by endogenizing some of the main forces affecting SHS - economic growth and population aging. Using a human-knowledge- 
based endogenous growth framework, we have attempted to address the four issues listed in the introduction. We show that SHS can reach steady state equilibrium level under given states of the art in health sciences along with population aging and economic growth. We also characterize the dynamic process leading to such equilibrium and quantify the major forces contributing to the level and trend of SHS over time and going forward via numerical simulations.

Relevance to the endogenous growth literature: Our stylized model offers a way to distinguish between two key components of human capital: education or knowledge capital, serving as an engine of per-capita income growth, and health capital reflected by probabilities of survival and health maintenance, serving as a facilitator of knowledge capital formation. A key result we derive through this distinction is the role of investment in life protection of children as a direct determinant of the long-term rate of economic growth, essentially because such investment works to protect the return on investment in education, and thus knowledge capital formation and growth. This framework also enables us to treat the levels and dynamic paths of health spending, population aging, and economic growth as components of a dynamic generalequilibrium system driven by optimal investments in fertility, education, and protective and remedial health care. The main implication of our analysis is that there is a steady state equilibrium solution for all the control and state variables of the model, including the share of health spending in GDP (SHS). Interestingly, some developed countries, including the US, have already begun exhibiting some slowdown in the growth of SHS in recent years (see Figure 5). But exogenous and discrete scientific breakthroughs in life sciences can shift upward the transition paths and steady state solutions of life expectancy, the share of health spending in GDP, and in some cases even the rate of per-capita income growth. 
The existence of an equilibrium steady state solution of the model is not an artifact of our restrictive OLG framework, which allows for only three overlapping generations and three finite phases of life. We can in principle allow for continuous expansion of the number of overlapping generations and life phases as longevity keeps growing, which would not change our basic results. The key to the equilibrium solution are the diminishing returns to health-care inputs in the production of life-saving and health maintenance services, or preventive and remedial care, within any given phase of life. This brings about a rising shadow price of life and health protection relative to consumption which counteracts, and ultimately checks, the influence of the continuous growth in the demand for health spending above that of GDP. Indeed, consistent with HJ, our "income elasticities" of demand for health spending especially at old age, as estimated in a GE context, clearly exceed unity for the generation of adults in our numerical analysis (calibrated to match current SHS). However, these elasticities affect the behavior of SHS only over its transitional dynamic path. The elasticities ultimately converge on a unitary value at the equilibrium steady state of growth.

As stressed in section $\mathrm{V}$, our numerical analysis cannot be expected to yield precise forecasts of the steady state solutions for SHS or LE (see fn. 20) largely because our model does not account for the separate role of government in determining health spending, and is subject to a restrictive life-cycle structure. Yet the dynamic patterns of the simulated paths of SHS, fertility, life expectancy, and population aging are consistent with the US historical trends. The model is also consistent with a rather stable long term growth rate in GDP per-capita, indicating that the average shares of per-capita income spent on rearing and protecting children, $v$ and $I_{l}$, have not shifted significantly over the long haul. 
Relevance to the literature on health and growth: The main new insight our paper offers about the association between health and growth is that shocks in exogenous parameters that raise investment in the probability of survival to the productive phase of adulthood will increase the level of investment in education and knowledge, and thus the steady-state rate of per-capita income growth. However, as Table 1 and our analysis in section $\mathrm{V}$ indicate, not all exogenous parameter shocks have similar effects on life expectancy or economic growth. For example, our numerical analysis indicates that exogenous breakthroughs in health sciences, which have led to significant increases in survival probabilities to old age $\left(\Gamma_{2 H}^{U}\right.$ and $\left.\eta_{2}\right)$, do not affect investment in education, but they do raise SHS and life expectancy. Also, some beneficial shocks in life-saving technologies (a reduction in $D_{01}$ and $\varepsilon_{1}$ in equation 6) generate favorable effects on life expectancy but may diminish the productivity of investment in life protection, and may thus lead to an inverse relation between life expectancy and economic growth.

Likewise some shocks in exogenous parameters raising remedial medical care at old age may increase life expectancy, but will have no effect on the rate of economic growth and knowledge formation. These ambiguous relations concerning the association between life expectancy and educational attainments or growth may further explain the results reported in both AJ (2007) and Hansen (2013).

More generally, changes in parameters that raise investments in or the efficacy of knowledge capital or survival probabilities to adulthood and especially old age may be the main forces that drive up the income share of health spending, SHS, over the period of transition to a stable steady-state equilibrium.

Some policy ramifications: Our numerical analysis in section III.4.B indicates that the steady-state level of SHS may rise just 3-4 percentage points above its current level - from 17.9 
to 21.43 in 4 generations. The increase may be well understated because our model does not allow for any government involvement in health financing or for inefficient use of medical services under actuarially unfair health insurance. Yet it indicates the critical role shadow prices can play in bringing about balanced growth equilibrium and an upper limit to health spending as a fraction of the economy, under any given state of the arts in medical and biological sciences.

So while the analysis applies to a private economy with a competitive health care system and actuarially fair health insurance, it implies that efficient reforms in the current mixed system that seek to restrain the growth in SHS and increase the speed of its convergence on a steady state level following breakthroughs in life sciences, will benefit from relying on the rationing role of explicit marginal cost pricing, especially in the case of costly new medical treatments, even if we allow basic services to be universally subsidized. Not doing so would inevitably entail balancing the system through some form of physical rationing, which is far less efficient.

The analysis also puts an emphasis on investment in children's survival to adulthood as yielding high social return because they protect, and thus induce investments in the knowledge component of human capital which promotes economic growth. By the same token policies that induce larger investment in education increase the motivation to protect this investment by investing in life protection and adopting healthier lifestyle which promote the probability of survival to older age. By contrast, the analysis indicates the limitations of health financing policies which encourage the use of remedial care services covered by reimbursement insurance policies, as the latter encourage excessive use of remedial medical services at the expense of the more individually and socially productive preventive medical care and life protection. 


\section{References}

Acemoglu, D., and S. Johnson (2007), "The Effect of Life Expectancy on Economic Growth." Journal of Political Economy, 115:925-85.

Becker, G.S., K. Murphy, and R. Tamura (1990), "Human Capital, Fertility, and Economic Growth", Journal of Political Economy, 98, S12-S38.

Bleakley, H. (2007), "Disease and Development: Evidence from Hookworm Eradication in the American South", Quarterly Journal of Economics, 122(1), 73-117.

Ehrlich, I. (2007), "The Mystery of Human Capital as Engine of Growth, or Why the US Became the Economic Superpower in the 20th Century", NBER Working Papers 12868.

Ehrlich, I. (2000), "Uncertain Lifetime, Life Protection, and the Value of Life Saving”, Journal of Health Economics, 19(3), 341-367.

Ehrlich, I., and H. Chuma (1990), "TheDemand for Longevity and the Value of LifeExtension." Journal of Political Economy, 98:761-82.

Ehrlich, I. and J. Kim (2005), "Endogenous Fertility, Mortality and Economic Growth: Can a Malthusian Framework Account for the Conflicting Historical Trends in Population?," Journal of Asian Economics, 16(5), 789-806,

Ehrlich, I. and J. Kim (2007), "Social Security and Demographic Trends: Theory and Evidence from the International Experience", Review of Economic Dynamics, 10, 55-77.

Ehrlich, I. and F. Lui (1991), "Intergenerational Trade, Longevity, and Economic Growth", Journal of Political Economy, 99, 1029-1059.

Ehrlich, I. and Y. Yin (2005), "Explaining Diversities in Age-Specific Life Expectancies and Values of Life Saving: A Numerical Analysis", Journal of Risk and Uncertainty, 31(2), 129-162.

Gruber, J. (2006) "A Tax-Based Estimate of the Elasticity of Intertemporal Substitution.", Working Paper no. 11945, NBER, Cambridge, MA.

Haines, Michael (1998), "Estimated Life Tables for the United States, 1850-1910", Historical Methods, 31(4), $149-169$.

Hall, R. and C. Jones (2007), "The Value of Life and the Rise in Health Spending", Quarterly Journal of Economics, 122(1), 39-72.

Juster, F. and F. Stafford (1991), "The Allocation of Time: Empirical Findings, Behavioral Models, and Problems of Measurement", Journal of Economic Literature, 29. 
LLS (2013), Facts 2013, The Leukemia \& Lymphoma Society, online material, http://www.lls.org/content/nationalcontent/resourcecenter/freeeducationmaterials/generalcancer/ pdf/facts.pdf.

Lucas, A. (2010), "Malaria Eradication and Educational Attainment: Evidence from Paraguay and Sri Lanka", American Economic Journal: Applied Economics, 2, 46-71.

Lucas, R. (1988), "On the Mechanics of Economic Development," Journal of Monetary Economics, 22(1), 3-42.

Maddison, A. (2003), The World Economy: Historical Statistics, OCED, Paris.

National Center for Health Statistics (various years), National Vital Statistics Reports. 


\title{
Footnotes
}

\begin{abstract}
${ }^{1}$ This has been the convention in the human-capital based endogenous growth literature, on the implicit assumption that human capital and physical capital are complements in production.

${ }^{2}$ Although restricting the life span to just three generations puts a limit on human longevity and life expectancy in this framework, this does not automatically assures an interior-equilibrium solution for our key variables, nor would our basic results change if we allowed for continually increasing life phases and overlapping generations.
\end{abstract}

${ }^{3}$ Our model expands the basic elements of the endogenous growth models of Lucas (1987), Becker, Murphy, and Tamura (1990), and especially Ehrlich and Lui (1991) and Ehrlich and Kim (2007) to integrate health and life expectancy as a basic endogenous variable in addition to fertility and human capital formation.

${ }^{4}$ A technical reason for modeling survival probabilities rather the health stock as key "state variables" is that we cannot model the evolution of the health stock as a continuous process within our OLG framework, as we need to allow for discreet changes in the conditional probabilities of survival across different phases of life and the corresponding overlapping generations. We distinguish, however, investment in life protection which enhances survival to the next phase of life, and health maintenance or remedial care, which enhances lower morbidity within a given phase. These distinctions follow the formal analysis in Ehrlich (2000) and Ehrlich and Yin (2005).

${ }^{5}$ In this overlapping-generations framework, parents thus maximize children's lifetime utility indirectly through the "bequest" they leave in the form of investments' in children's well-being, survival, and productive capacity, so the latter can then mature to assume the productive decision-making role as parents.

${ }^{6}$ The choice of this functional form is dictated by the need to account for upper and lower limits of key control and state variables (e.g., $\pi_{j}$ ) and to allow for staggered transitional paths for these variables over the transition to the steady-state growth equilibrium. Power functions, e.g., would not qualify. The function exhibits diminishing returns to both increments in inputs $\left(I_{j}\right)$ and outputs $\left(\pi_{\mathrm{j}}\right)$. A decrease in $D_{j}$ and an increase in $\Gamma_{j H}{ }^{U}$ raise the marginal products of $I_{j}$, but while the rise in $\Gamma_{j H}{ }^{U}$ also raises the level of $\pi_{j}$, the fall in $D_{j}$ lowers it. The assumption of diminishing returns is logically justified by the fact that within a given phase of life and the limitation of human physiology and medical technology, doubling health care inputs cannot double survival probabilities on the margin. Note that proposition 1 in the following subsection holds for any functional form of equation (6) that is concave in $I_{j}$.

${ }^{7}$ In a growth context, the continuous formation of knowledge capital - our engine of growth - can also be positively correlated with continuous advances in medical technology. Equation (6) also allows, however, for breakthroughs in medical technology which can raise the upper bound of survival probability or lower the rate at which it may depreciate at adulthood or old age, as given by $\mathrm{D}_{\mathrm{j}}$. We take the levels of $\Gamma_{j H}{ }^{U}$ and $\Gamma_{j L}$ in this analysis to be constant in all generations. In our numerical analysis we use historical data to calibrate the value of $\Gamma_{j L}$. See section III.3.A.

${ }^{8}$ Equation (6c) is the conventional definition of LE in a given period, t. We can alternatively use the cohort definition of LE by replacing $\pi_{1 \mathrm{t}}$ with $\pi_{1, \mathrm{t}-1}$. The difference between the two, however, vanishes in a steady state.

${ }^{9}$ In equation (9a), the shadow price of life protection represents the value to parents from a marginal increase in the survival probability of children to adulthood, as determined by the companionship function.

${ }^{10}$ Technically, the numerical solution of the baseline model is derived from the calibrated simulations of the extended model after shutting down remedial care and the health benefits it yields as an independent good. The parameter values we adopt from the extended model are: $A=9.5593, v=0.03, \beta=1.23, B=0.235, \sigma=0.5$, 
$\delta=0.015, \theta=0.1955, D_{l}=0.000012, \varepsilon_{l}=2, \eta_{1}=1, \Gamma_{l L}=0.67, \Gamma_{l H}{ }^{U}=0.99, f_{l}=0.9596, D_{2}=0.016, \varepsilon_{2}=2.5$, $\eta_{2}=1, \Gamma_{2 L}=0.37, \Gamma_{2 H}{ }^{U}=0.95$, and $f_{2}=0.9368$. See section III.3.A for a complete analysis.

${ }^{11}$ Though it may mainly speed up recovery from illness, remedial care may confer life protection or "preventive" benefits as well, thus enhancing survival to the next phase of life, $\pi_{\mathrm{j}}$. In our model, however, the protective component of remedial care is accounted for as "investment in life protection" $\left(I_{j}\right)$. Our more narrowly defined "remedial care" at adulthood and old age is then restricted to lower time loss due to non-life-threatening illness within these phases. Note that parental investment in children's well-being (v) and survival to adulthood, $I_{l}$ includes both protective and remedial, the benefits of which are motivated by the companionship function, $\mathrm{C}_{3, t+1}$.

${ }^{12}$ To simplify an otherwise quite complex computational analysis, we focus on the beneficial effects of healthy time on consumption and abstract from any effects of remedial care on productive capacity at both adulthood and the oldage phase of retirement. This would not affect, however, the basic qualitative results of the model. In the context of our analytical framework, this would not affect, however, the basic qualitative results of the model.

${ }^{13}$ We use the term remedial medical care at adulthood and old age to denote spending on health maintenance, or recovery from non-fatal diseases, since remedial care can also be a part of life protection. In the case of children, spending on health maintenance as consumption is subsumed under the parent's cost of bearing and rearing children $(v n)$ as well as investing in their survival to adulthood $\left(n I_{l}\right)$, both motivated by the parental altruism function (4).

${ }^{14}$ The normalization factor $\mathrm{N}$ is added to enable a linkage between the numerical analyses used in the baseline and the extended model. See the discussion in section 3.A.

${ }^{15}$ This makes the absolute measure of health benefits $H B_{t}$ comparable to that of conventional goods, $X_{t}$, otherwise in a growth equilibrium the magnitude of $H B_{t}$ would become negligible relative to that of $X_{t}$. Since we do not model separately the choice of consumption vs. labor time, we link the unit value of the latter to that of total time or production capacity, assuming that the fraction of healthy time within any given phase of life augments the productivity of time in all its uses. In the numerical analysis we specify $c_{j}^{e}$ as an arbitrary fraction (1/2) of total production capacity $\left(\mathrm{H}_{\mathrm{t}}+\mathrm{H}^{0}\right)$ without loss of generality, since the specific fraction has no effect on the results.

${ }^{16}$ We assume that representative agents at adulthood and old age benefit from the same medical knowledge at time $t$, $H_{t}$, due to spillover effects - all physicians share such knowledge in providing remedial care. Allowing for different education levels for the overlapping generations $\left(H_{t}\right.$ and $\left.H_{t-1}\right)$ has a negligible effect in the numerical analysis.

${ }^{17}$ As recent evidence indicates, the incidence of serious diseases, such as Alzheimer has been increasing over time as the average age of baby boomers entering old age has been on the rise. Note that at time $t$, the representative agent in the phase of adulthood has a predetermined probability of survival $\pi_{l t}$, but the corresponding agent in the old age phase at time $\mathrm{t}+1$ has a probability of survival $\pi_{2, t-1}$ as determined by the previous generation (t-1).

${ }^{18}$ Recall that $\theta$ is the share of the young adult's full income the latter pays to support the elderly, and thus $\left(\mathrm{m}_{2, \mathrm{t}-1} \theta\right)$ is the full-income share of remedial care spent by the elderly on remedial care, where $\mathrm{m}_{2, \mathrm{t}-1}=\mathrm{M}_{2, \mathrm{t}-1} / \mathrm{TC}_{2, \mathrm{t}-1}$.

${ }^{19}$ The resulting calibrated parameters are: $A=9.5593, \beta=1.23, B=0.235, \theta=0.1955, D_{1}=0.000012, \varepsilon_{1}=2, \eta_{1}=1$, $\Gamma_{l H}{ }^{U}=0.99, f_{1}=0.9596, D_{2}=0.016, \varepsilon_{2}=2.5, \eta_{2}=1, \Gamma_{2 H}{ }^{U}=0.95, f_{2}=0.9368, \rho=-0.2, N=2.4943$, $c_{j}^{e}=0.5\left(\mathrm{H}_{\mathrm{t}}+\mathrm{H}^{0}\right), L_{01}=422, \gamma_{1}=1, \varphi_{1}=0.1, L_{02}=1410, \gamma_{2}=2, \varphi_{2}=0.1, H T_{H}^{U}=674, \eta_{m}=1, f_{m}=0.94, D_{m l}=0.221$, $\varepsilon_{m, 1}=1.5, D_{m 2}=78$, and $\varepsilon_{m 2}=2$. Note that most of the parameters representing preferences are taken from Ehrlich and Kim (2007), which are compatible with consensus values in the literature. The fraction 0.5 multiplying $c_{j}^{e}$ is irrelevant in the calibration. Setting it to 0.6, e.g., just rescales other parameters without changing the solutions.

${ }^{20} \mathrm{~A}$ comment is warranted about the steady-state value of life expectancy, projected to be 81.37. This value is an artifact of our numerical identification of all phases of life to last over 30 years, i.e., for the retirement phase of old 
age to end at age 90 . Our model can be easily extended by allowing the last phase of life to be longer without affecting our basic results. If we allow for that phase to be extended to 35 years, rather than 30 , which is currently more realistic, our estimated life expectancy would rise from its current 79.6 to 85.2 in the steady state.

${ }^{21}$ In this context, we have also conducted an additional experiment by eliminating the role of knowledge capital in the life protection and remedial medical care production functions (6) and (12). As indicated in our analysis of section II.4, this would lead mainly to a shortening of the transition to a new growth equilibrium steady state. Indeed, this is what we find. Our experiment shows that SHS would then converge on a new equilibrium steady state of SHS in just 3 generations.

${ }^{22}$ The effects differ slightly for this pair of parameters ( $A$ vs. $\Gamma_{1 H}^{U}$ or $\eta_{I}$ ) in that $A$ does not affect the production function of life protection at young age (or adulthood) and thus $h^{*}, I_{1}^{*} \pi_{1}^{*}$ as implied by equations (8a) and (9a).

${ }^{23}$ The "wealth elasticity" of total medical spending is computed in our numerical analysis as $1+\mathrm{d} \ln (\mathrm{SHS}) / \mathrm{d} \ln (\mathrm{Y})$, where Y stands for full income. We discretize the total differentiation, which accounts for all feedback effects, by estimating the percentage change in SHS divided by percentage change in $\mathrm{Y}$ as estimated for generation 2.

${ }^{24}$ The net growth rate, g, was measured as the average growth rate in per-capita GDP between 1960 and $1985 ; \pi_{1}$ was measured as the probability of survival from age 0 to 25 in 1960 or the closes year before it for which data were available; and $\pi_{2}$ was similarly measured as the probability of survival from age 50 to 75 , all in $\log$ form. The weighted OLS regression included both probability measures and initial (1960) per-capita GDP as covariates. The inclusion of the latter was required by the model.

${ }^{25}$ This finding at the macro level supports recent literature indicating that health investment at early childhood produce favorable schooling benefits at later ages (see Bleakley, 2007 and Lucas, 2010).

${ }^{26}$ Note also that by our model the yearly growth rate of income is measured as $(1+\mathrm{g}) \equiv\left(\mathrm{H}^{0}+\mathrm{H}_{\mathrm{t}+1}\right) /\left(\mathrm{H}^{0}+\mathrm{H}_{\mathrm{t}}\right)=\mathrm{Ah}+$ $\left[\mathrm{H}^{0} /\left(\mathrm{H}^{0}+\mathrm{H}_{\mathrm{t}}\right)\right]$. If the annual growth rates over the long sample period approximate the long-term rate of growth, this measure converges on the steady state growth rate $\mathrm{Ah}^{*}$, and a transitional term that is negatively related to the concurrent level of per-capita GDP. 
Figure 1. US Health Spending by Private and Public Components GDP Shares 1960-2011

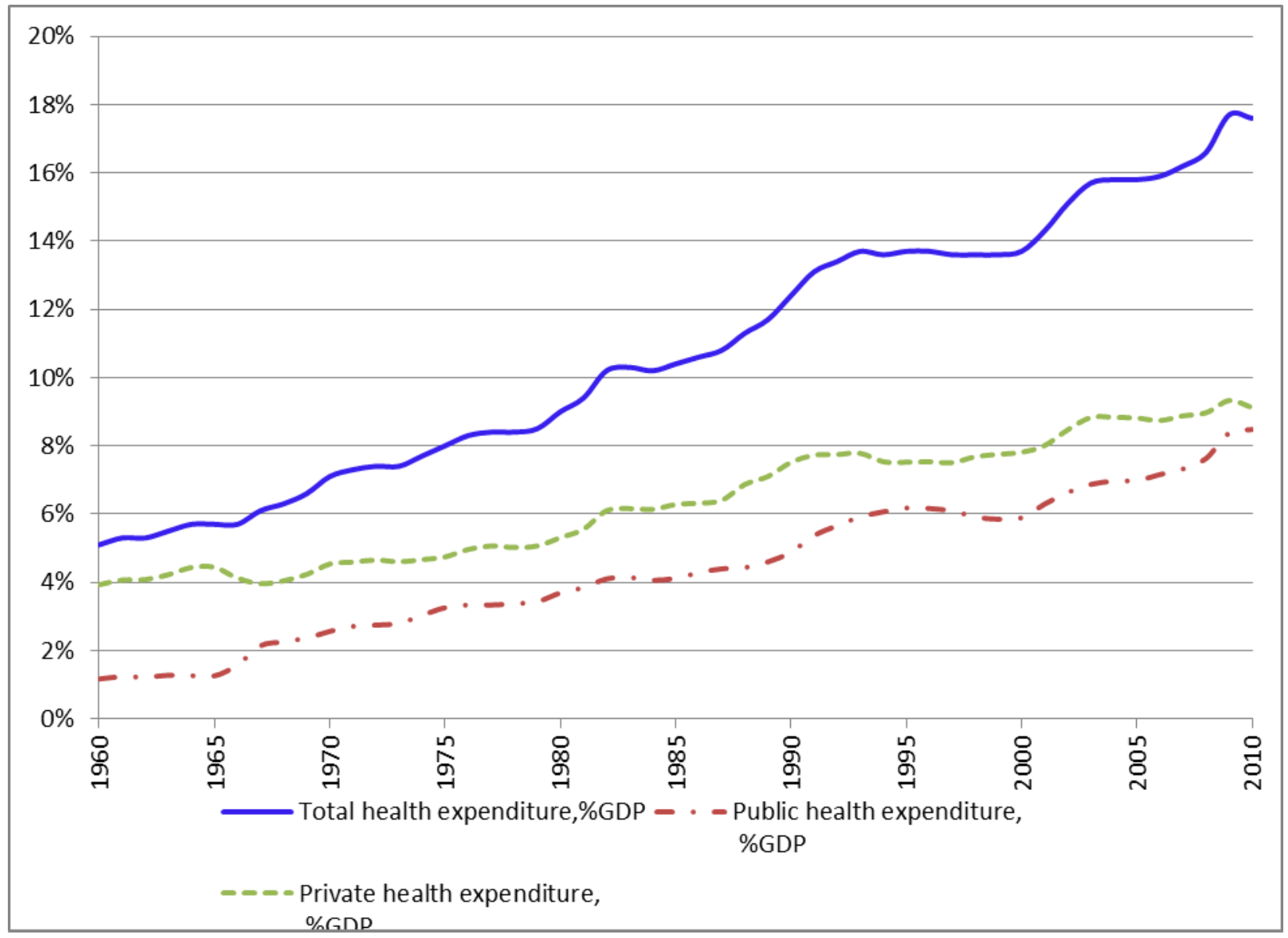


Figure 2. Health, Aging, and Endogenous Economic Growth - Possible Directions of Causality

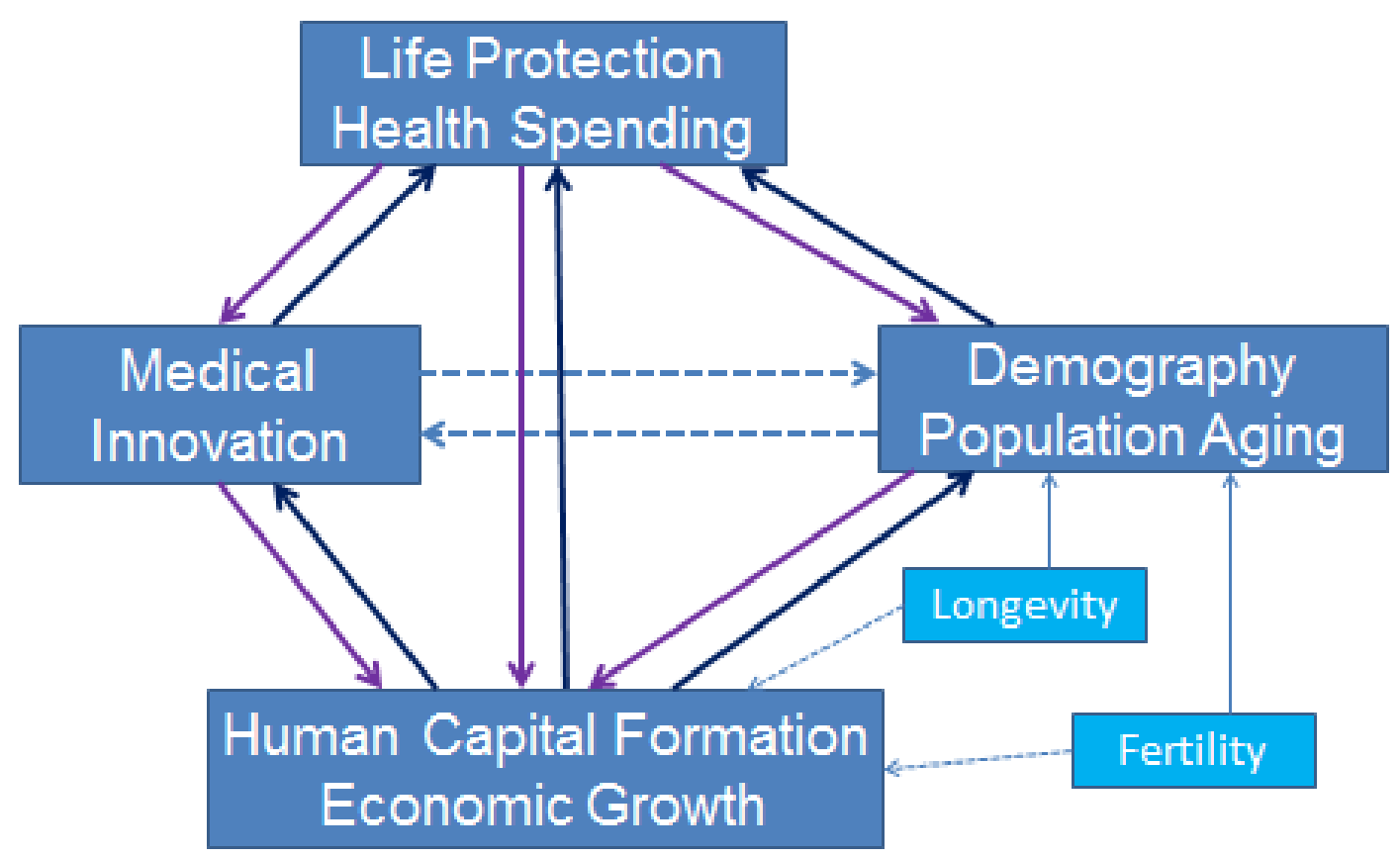


Figure 3-1 Transitional Paths of Endogenous Variables in the Extended Model
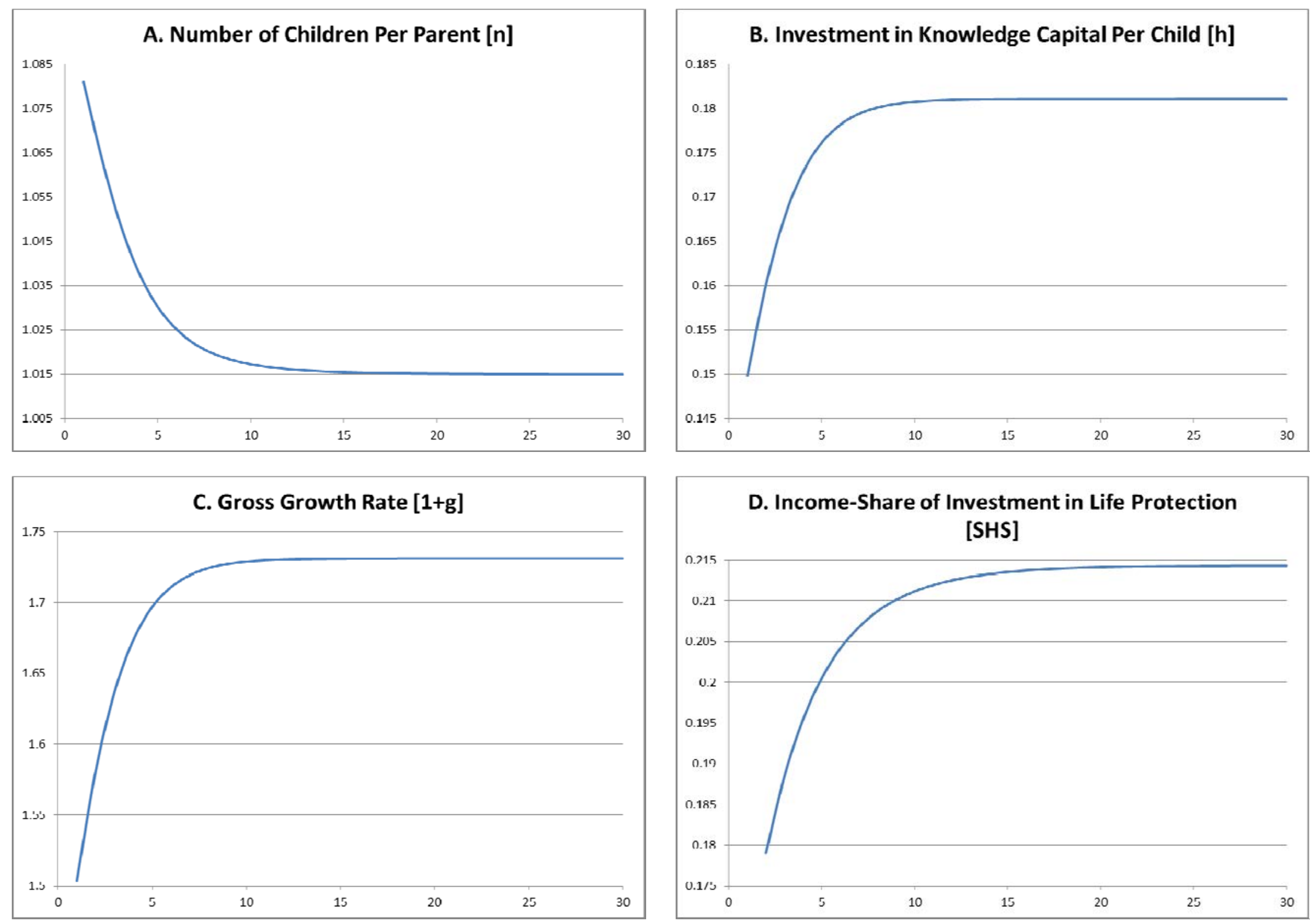

See text for calibrated parameters. All charts (except for SHS and aging) start at generation 1; charts of SHS and Aging start at generation 2. 
Figure 3-2 Transitional Paths of Endogenous Variables in the Extended Model
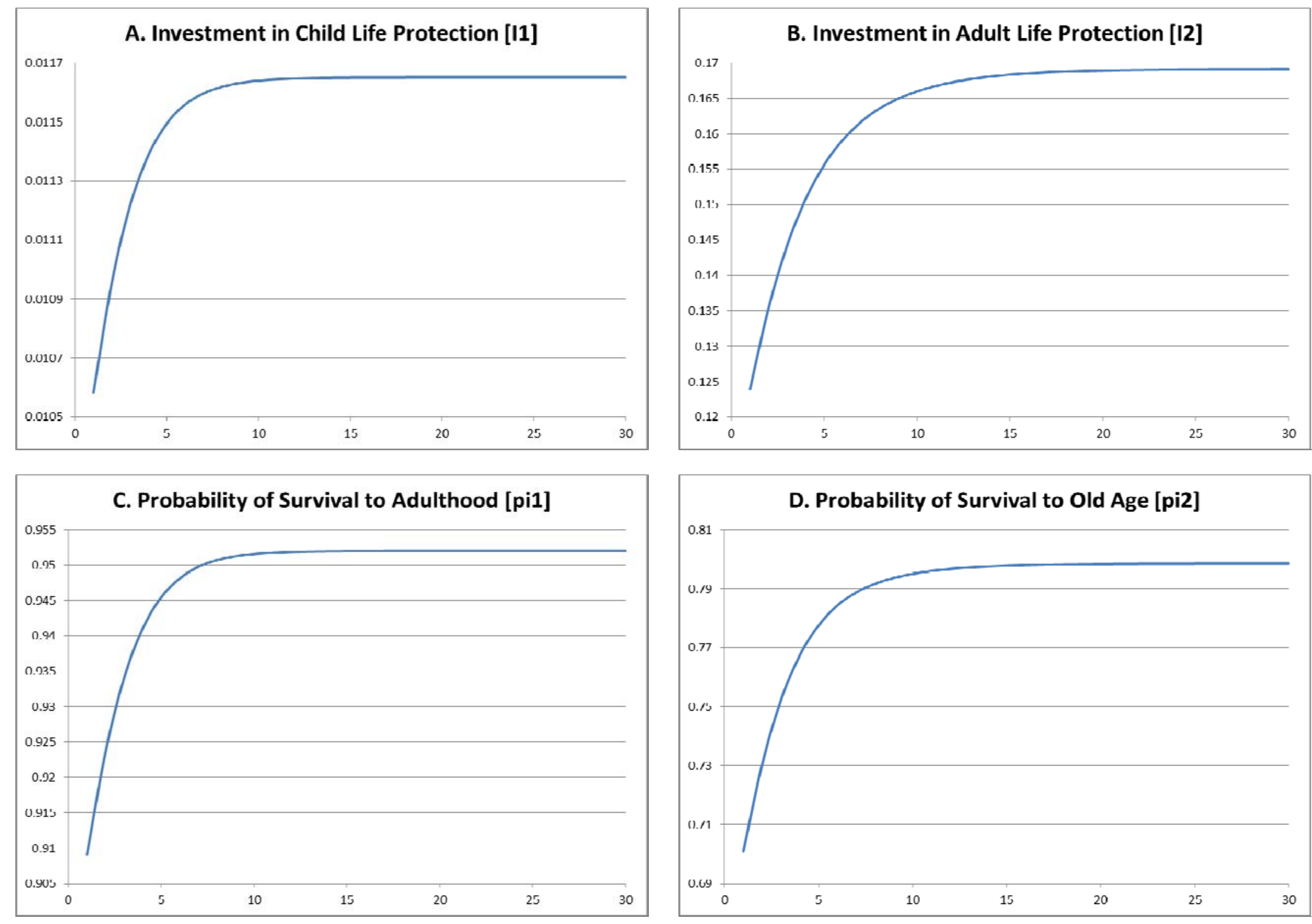

See notes to Figure 3-1. 
Figure 3-3 Transitional Paths of Endogenous Variables in the Extended Model
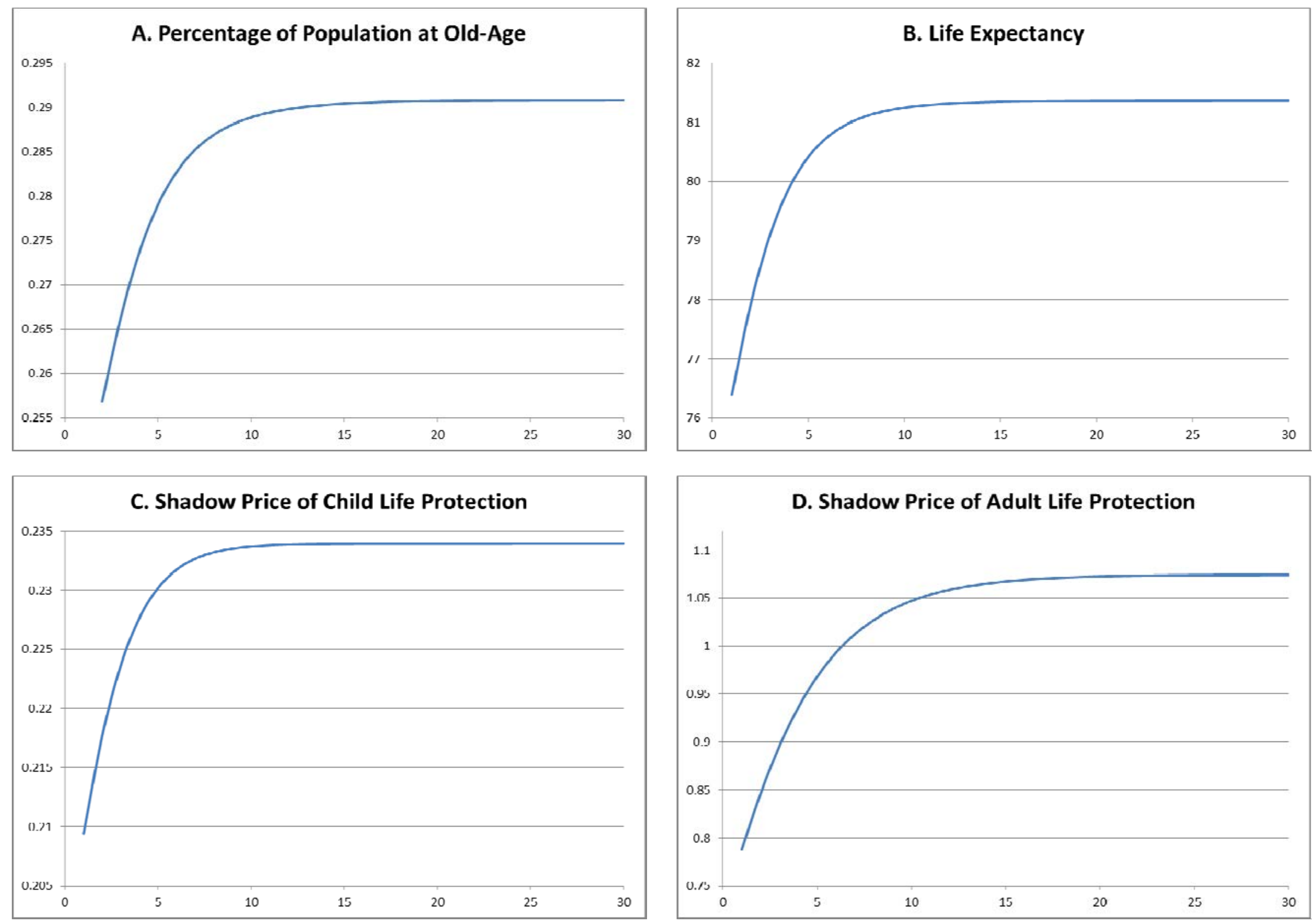

See notes to Figure 3-1. 
Figure 3-4 Transitional Paths of Endogenous Variables in the Extended Model
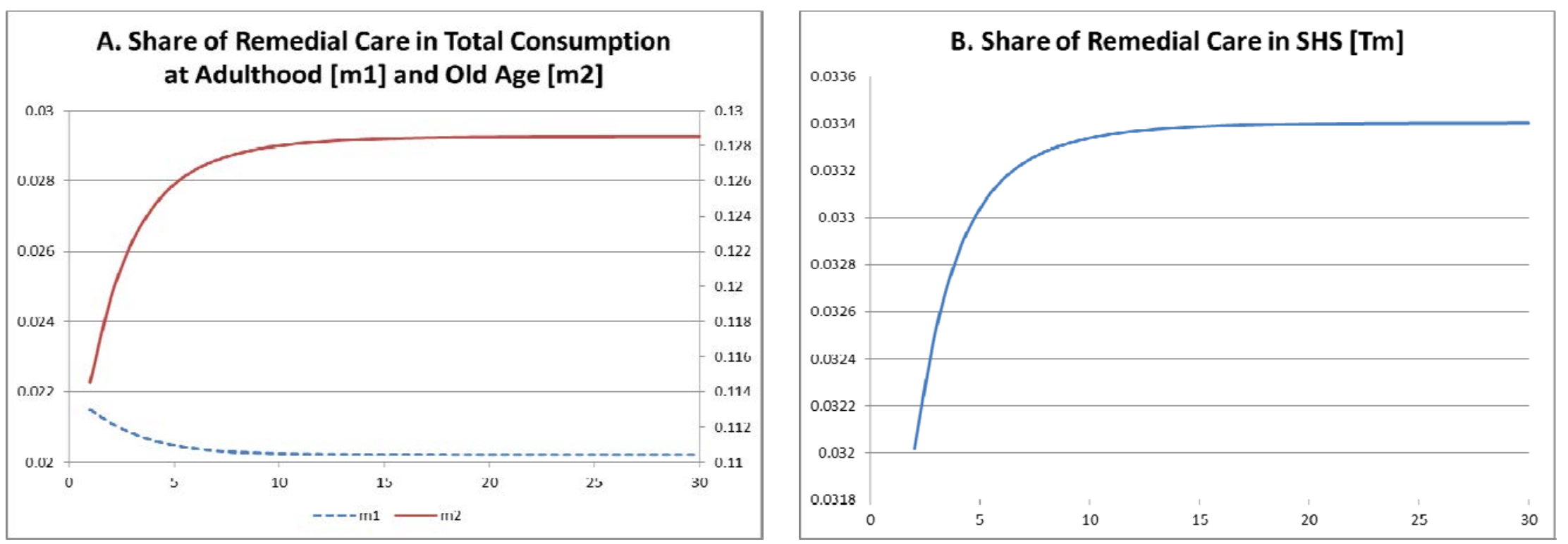

See notes to Figure 3-1. 
Figure 4 Transitional Paths of Endogenous Variables: Baseline vs. Extended Models
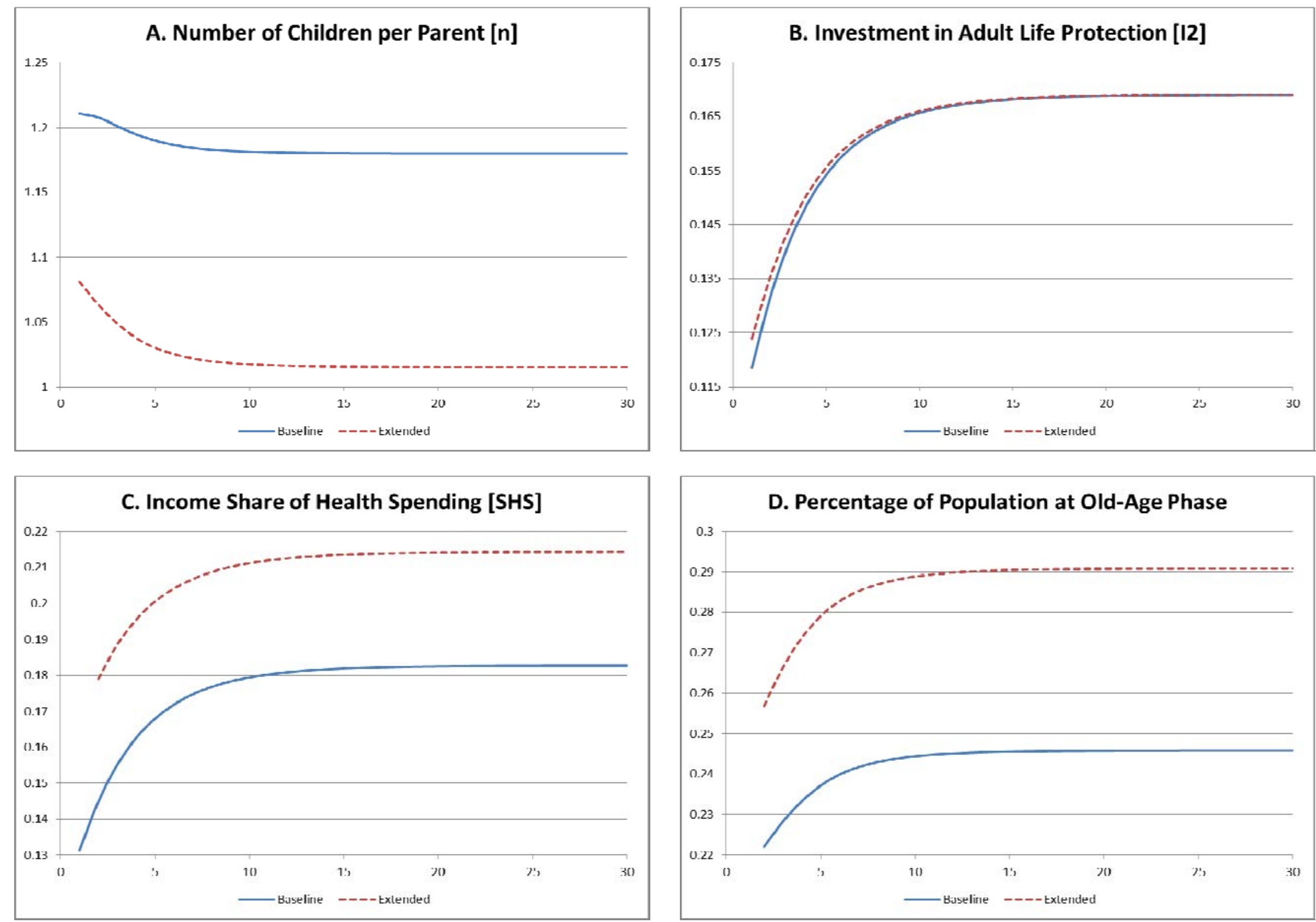

See notes to Figure 3-1. 
Figure 5 Share of Health Spending in Different Health Care Systems

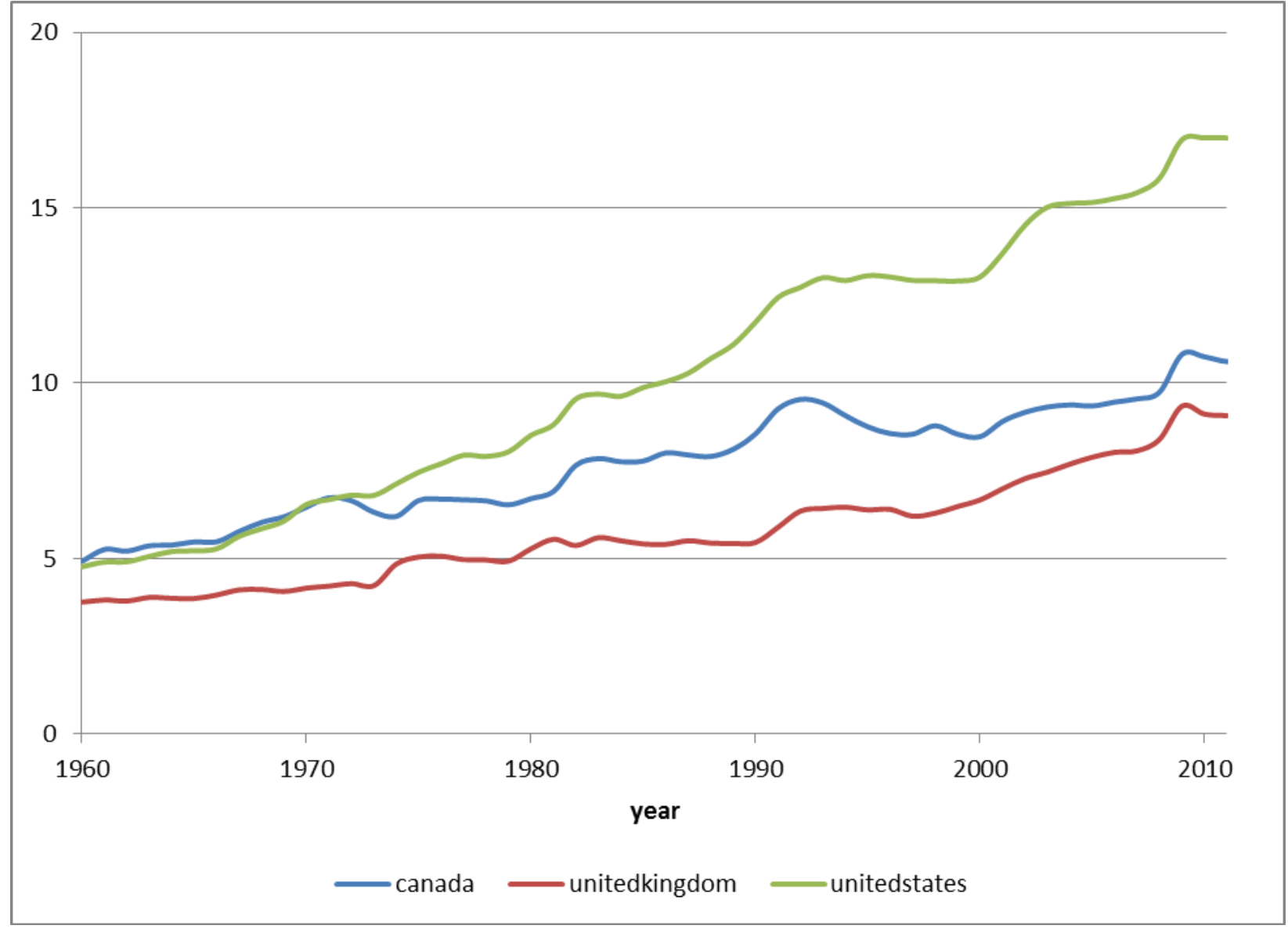


Table 1 Comparative Dynamics for the Extended Model*

\begin{tabular}{|c|c|c|c|c|c|c|c|c|c|c|c|c|c|c|c|c|}
\hline \multirow{2}{*}{$\begin{array}{c}\text { Shift in } \\
\text { calibrated } \\
\text { parameters }\end{array}$} & \multicolumn{16}{|c|}{ Endogenous Variables } \\
\hline & $\mathrm{n}$ & $\mathrm{h}$ & $\mathrm{I}_{1}$ & $\mathrm{I}_{2}$ & $\Omega$ & $1+g$ & Aging & LE & $\mathrm{m}_{1}$ & $\mathrm{~m}_{2}$ & $\mathrm{HB}_{1}$ & $\mathrm{HB}_{2}$ & $x_{1}$ & $x_{2}$ & $\pi_{1}$ & $\pi_{2}$ \\
\hline A & + & 0 & 0 & + & + & + & - & + & - & + & + & + & + & + & 0 & + \\
\hline $\mathrm{v}$ & - & + & + & + & - & + & + & + & + & - & + & + & + & + & + & + \\
\hline $\mathrm{B}$ & + & 0 & 0 & + & + & 0 & - & + & - & + & - & - & - & + & 0 & + \\
\hline$\delta$ & - & 0 & 0 & - & - & 0 & + & - & + & - & + & + & + & - & 0 & - \\
\hline$\sigma$ & - & 0 & 0 & + & + & 0 & + & + & + & $-/+$ & + & - & + & - & 0 & + \\
\hline$\beta$ & + & - & - & - & + & - & - & - & - & + & - & - & - & - & - & - \\
\hline$\theta$ & - & 0 & 0 & - & + & 0 & + & - & - & + & - & + & - & + & 0 & - \\
\hline$D_{1}$ & - & + & + & - & + & + & + & - & + & - & + & + & + & + & - & - \\
\hline$\varepsilon_{1}$ & - & + & + & - & + & + & + & - & + & - & + & + & + & + & - & - \\
\hline$\Gamma_{1 H}^{U}\left(\eta_{1}\right)$ & + & + & + & + & + & + & - & + & - & + & + & + & + & + & + & + \\
\hline$D_{2}$ & - & 0 & 0 & + & + & 0 & + & - & + & - & + & + & + & - & 0 & - \\
\hline$\varepsilon_{2}$ & - & 0 & 0 & + & + & 0 & + & $-/+$ & - & $-/+$ & - & $+/-$ & - & - & 0 & $-/+$ \\
\hline$\Gamma_{2 H}{ }^{U}\left(\eta_{2}\right)$ & + & 0 & 0 & + & + & 0 & - & + & - & + & - & - & - & - & 0 & + \\
\hline$\rho$ & - & 0 & 0 & - & - & 0 & + & - & - & - & - & + & + & - & 0 & - \\
\hline $\mathrm{HT}_{\mathrm{H}}{ }^{\mathrm{U}}\left(\eta_{\mathrm{m} 1}\right)$ & - & 0 & 0 & - & - & 0 & + & - & - & - & + & + & + & $+/-$ & 0 & - \\
\hline$D_{m 1}$ & + & 0 & 0 & + & + & 0 & - & + & + & + & - & + & - & + & 0 & + \\
\hline$\varepsilon_{\mathrm{m} 1}$ & + & 0 & 0 & + & + & 0 & - & + & + & + & - & + & - & + & 0 & + \\
\hline$D_{m 2}$ & + & 0 & 0 & - & + & 0 & - & - & + & + & + & - & + & - & 0 & - \\
\hline$\varepsilon_{\mathrm{m} 2}$ & + & 0 & 0 & - & + & 0 & - & - & + & + & + & - & + & - & 0 & - \\
\hline \multicolumn{17}{|c|}{ Value of Endogenous Variables at Steady State } \\
\hline Extended Model & 1.015 & 0.181 & 0.0117 & 0.169 & 0.2143 & 1.01846 & 0.291 & 81.37 & 0.02 & 0.129 & & & & & 0.952 & 0.799 \\
\hline Baseline Model & 1.180 & 0.181 & 0.0117 & 0.169 & 0.183 & 1.01846 & 0.246 & 81.36 & & & & & & & 0.952 & 0.798 \\
\hline
\end{tabular}

* Quantitative results for steady state solutions. Results for $\mathrm{X}_{1}, \mathrm{X}_{2}, \mathrm{HB}_{1}$, and $\mathrm{HB}_{2}$ are shown for the latest computed generation. 
Table 2: Impact of Model Parameters on the steady-state level of SHS*

\begin{tabular}{|c|c|c|}
\hline \multirow[b]{2}{*}{ Parameter } & \multicolumn{2}{|c|}{ Elasticities } \\
\hline & $-10 \%$ & $+10 \%$ \\
\hline A & 0.314 & 0.272 \\
\hline$v$ & -0.0386 & -0.0344 \\
\hline B & 0.178 & 0.153 \\
\hline$\delta$ & -0.253 & -0.263 \\
\hline$\sigma$ & 0.217 & 0.321 \\
\hline$\beta$ & 0.0418 & 0.0715 \\
\hline$\theta$ & 0.0362 & 0.0243 \\
\hline $\mathrm{D}_{1}$ & 0.0068 & 0.0061 \\
\hline$\varepsilon_{1}$ & 0.062 & 0.0515 \\
\hline$\eta_{1}$ & $7.48 \times 10^{-5}$ & $2.71 \times 10^{-14}$ \\
\hline$\Gamma_{1 H}^{U}$ & 0.369 & 0.331 \\
\hline$D_{2}$ & 0.0745 & 0.0646 \\
\hline$\varepsilon_{2}$ & 0.156 & 0.115 \\
\hline$\eta_{2}$ & 0.000268 & $9.54 \times 10^{-14}$ \\
\hline$\Gamma_{2 H}{ }^{U}$ & 0.961 & 0.800 \\
\hline$\rho$ & -0.674 & -0.677 \\
\hline $\mathrm{HT}_{0}{ }^{\mathrm{U}}$ & -0.214 & -0.185 \\
\hline$D_{m 1}$ & 0.0123 & 0.0114 \\
\hline$\varepsilon_{\mathrm{m} 1}$ & 0.062 & 0.0588 \\
\hline$D_{m 2}$ & 0.0335 & 0.0314 \\
\hline$\varepsilon_{\mathrm{m} 2}$ & 0.053 & 0.043 \\
\hline
\end{tabular}

* The table summarizes the impacts of model parameter on the steady-state level of SHS in the extended model. We allow each parameter to shift down $10 \%$ or up $10 \%$, and then calculate the percentage change in the steady-state values of SHS. The recorded results are thus approximate elasticities. 